\title{
On testing the role of genetic asymmetries created by haplodiploidy in the evolution of eusociality in the Hymenoptera
}

\author{
RAGHAVENDRA GADAGKAR \\ Centre for Ecological Sciences and Centre for Theoretical Studies, Indian Institute of \\ Science, Bangalore 560 012, India
}

MS received 22 March 1991

\begin{abstract}
The haplodiploid genetic system found in all Hymenopterans creates an asymmetry in genetic relatedness so that full-sisters are more closely related to each other than a mother is to her daughters. Thus Hymenopteran workers who rear siblings can obtain higher inclusive fitness compared to individuals who rear offspring. However, polyandry and polygyny reduce relatedness between workers and their sisters and thus tend to break down the genetic asymmetry created by haplodiploidy. Since the advent of electrophoretic analysis of variability at enzyme loci, several estimates of intra-colony genetic relatedness in the Hymenoptera have been published. To test the role of the genetic asymmetry created by haplodiploidy in the evolution of eusociality, I assume that workers are capable of investing in their brothers and sisters in their ratio of relatedness to them. I then compute a haplodiploidy threshold, which is the threshold relatedness to sisters required for workers to obtain a weighted mean relatedness of 0.5 to siblings and thus break even with solitary foundresses. When workers rear mixtures of sisters and brothers in an outbred population, the value of this threshold is 0.604 . An examination of the distribution of 185 estimates of mean genetic relatedness between sisters in Hymenopteran colonies shows that the values are well below the expected 0.75 for full sisters, both in higly eusocial as well as in primitively eusocial species although relatedness values in the latter are higher than in the former. Of the 177 estimates with standard error, 49 are significantly lower than the haplodiploidy threshold and 22 are significantly higher. Of the 35 species studied only 6 have one or more estimates that are significantly higher than the haplodiploidy threshold. For more than half the estimates, the probability of the relatedness value being above the haplodiploidy threshold is less than 0.5 . Reanalysis of these data using 0.5 as the threshold does not drastically alter these conclusions. I conclude that the genetic asymmetry created by haplodiploidy is, in most cases, insufficient by itself either to promote the origin of eusociality or to maintain the highly eusocial state.
\end{abstract}

Keywords. Evolution of eusociality; haplodiploidy; genetic relatedness; haplodiploidy threshold; Hymenoptera.

\section{Introduction}

The sterile worker castes found in all eusocial insects were often thought to present an obvious challenge to Darwin's theory of natural selection (Darwin 1859, pp. 268-273). The seminal work of W. D. Hamilton (Hamilton 1964a, b) constituted the first serious attempt to meet this challenge. Hamilton developed the concept of inclusive fitness and showed how fitness can also be gained through aiding close genetic relatives in addition to or, indeed, instead of producing offspring. An important reason for the instant appeal of this kin selection theory was the fact that there have been at least eleven independent origins of eusociality in the insect order Hymenoptera (Wilson 1971), a group in which haplodiploidy makes full-sisters 
more closely related to each other (coefficient of genetic relatedness, $r=0.75$ ) than a mother would be to her offspring $(r=0.5)$. (Although Pamilo and Crozier (1982) have correctly argued that the appropriate directionality of relatedness is from beneficiary to altruist, in keeping with common usage in the literature, I shall refer to the conditional probability that an allele present in individual $\mathrm{A}$ is also present in individual B as the genetic relatedness of A to B). This is in contrast to only two, or perhaps three, known origins of eusociality outside the order Hymenoptera (the termites and the naked mole rat and perhaps the aphids) [Wilson (1971); see Jarvis (1981) and Shermann et al. (1991) for the naked mole rat and Aoki (1982) and Ito (1989) for aphids]. Thus a Hymenopteran female may gain more inclusive fitness by helping her mother produce additional female offspring (who would be her sisters) than by starting a new nest and producing her own offspring. In other words, haplodiploidy can potentially facilitate selection for worker behaviour through kin selection. The validity of this so called haplodiploidy hypothesis depends of course on the realisation of such high levels of relatedness between workers and the brood they rear.

\section{Two problems with the haplodiploidy hypothesis}

There are, however, two main problems with the haplodiploidy hypothesis. The first is that although workers may be related to their full-sisters by a coefficient of genetic relatedness of 0.75 , they are related to their brothers by merely 0.25 . If workers are engaged in rearing equal numbers of brothers and sisters, the average relatedness to the brood they rear would be reduced to 0.5 which is no more than the relatedness between a mother and her offspring. Trivers and Hare (1976) suggested a way out of this difficulty by arguing that Hymenopteran workers who have access to brood consisting of full-sisters and brothers would be selected to skew investment in the ratio of $3: 1$ in favour of sisters. Although Alexander and Sherman (1977) have argued that the data used by Trivers and Hare (1976) do not support their prediction of such optimal sex investment ratios (see also, Grafen 1986, Nonacs 1986, Pamilo 1987, Boomsma 1989), their idea solves the problem at least in principle.

The second problem with the haplodiploidy hypothesis is that many Hymenopteran queens are known to mate multiply and concurrently use sperm from several males so that workers often rear mixtures of full- and half-sisters (coefficient of genetic relatedness between half-sisters $=0.25$ ) (reviewed in Starr 1984, Gadagkar 1985b, Page 1986). Because the actual levels of relatedness amongst the queen's daughters depend on the number of males she mates with and the manner in which she utilises sperm from different males, a solution to this problem, or even a complete appreciation of it, was not possible without measuring the levels of intra-colony genetic relatedness.

\section{Levels of intra-colony genetic relatedness}

With the advent of electrophoretic techniques for the detection of isozyme allele frequencies (Harris 1966; Hubby and Lewontin 1966; Lewontin and Hubby 1966) and their application to the measurement of genetic relatedness (Craig and Crozier 
1979; Pamilo and Varvio-Aho 1979; Pamilo and Crozier 1982; Pamilo 1984, 1989; Queller and Goodnight 1989), a large number of estimates of intra-colony genetic relatedness have now appeared in the literature. At least 26 publications are known to me which together provide over 185 estimates of intra-colony genetic relatedness in colonies of ants, honey bees, vespine wasps, swarm-founding wasps, primitively eusocial bees and primitively eusocial wasps (appendix 1). Clearly, the time is ripe for an objective evaluation of the role of genetic asymmetry created by haplodiploidy in the origin and maintenance of eusociality.

\section{Conceptual difficulties in testing the haplodiploidy hypothesis}

There appear to have been at least five conceptual difficulties in testing the haplodiploidy hypothesis.

\subsection{Conceptual difficulty 1 : Prediction of the haplodiploidy hypothesis}

The first difficulty appears to be the lack of a clearly stated falsifiable prediction of the haplodiploidy hypothesis. The main reason for this is that the terms kin selection and haplodiploidy hypothesis are used interchangeably and the benefits of altruism due to high genetic relatedness in social groups and those due to higher productivities in the group mode compared to the solitary mode, are mixed up. Low intra-colony genetic relatedness" is sometimes interpreted as a "significant challenge for kin selection theory" (Queller et al. 1988, p. 1155). On other occasions, low levels of intra-colony relatedness (even values less than 0.5 ) are not considered a serious problem because of the fact that "even when $r<1 / 2$, altruism can be favoured when the benefit is sufficiently higher than the cost." (Strassmann et al. 1989 , p. 269). To take one more example, $\operatorname{Kukuk}(1989$, p. 197) concludes her paper with the statement "The levels of relatedness in D. zephyrus colonies are high enough for kin selection to be important in the maintenance of worker altruism given environmentally caused limitations on the reproductive output of solitary females." (italics mine). All this is quite correct but does not permit us to test the role of haplodiploidy in the evolution of worker altruism. What values of relatedness, for instance, should be considered low enough to be unimportant for kin selection, given environmentally caused limitations on the reproductive output of solitary females? The answer is none, because any finite value of relatedness is sufficient for kin selection provided environmentally caused limitations in the reproductive output of solitary females are strong enough.

A useful way of stating Hamilton's rule is that an altruistic or worker allele will be favoured if

$$
n_{i} r_{i}>n_{o} r_{o},
$$

where $n_{i}$ is the number of individuals reared by a worker in a colony and $r_{i}$ is the average genetic relatedness between workers and the brood they rear. Similarly $n_{o}$ is the number of offspring that a solitary individual can rear and $r_{o}$ is her genetic relatedness to her offspring (Craig 1979; Gadagkar 1985a). When dealing with social insects it should be remembered that both $n_{i}$ and $n_{o}$ refer to reproductive individuals and not to workers; the number of workers produced before producing 
reproductives is irrelevant here. In all theoretical arguments in the rest of this paper, sisters of workers will mean reproductive sisters, be it while discussing the number reared or genetic relatedness to them. It is important to realise that inequality (1) can be achieved in two different ways. The first is if $n_{i}>n_{o}$ even when $r_{i} \leqslant r_{o}$. The second is if $r_{i}>r_{o}$ even when $n_{i} \leqslant n_{o}$. When inequality (1) is achieved due to the second reason mentioned above, the species in question may be said to be genetically predisposed to the evolution of eusociality (Gadagkar 1985a). Such genetic predisposition is a prediction of the haplodiploidy hypothesis. In other words, it is only when inequality (1) is achieved because $r_{i}>r_{o}$ while $n_{i} \leqslant n_{o}$ that the haplodiploidy hypothesis should be considered as being validated. In short, the question we should be asking is whether asymmetries in genetic relatedness alone are sufficient to select for worker behaviour in the Hymenoptera. Thus low values of $r_{i}$ should be regarded as falsifying the prediction of the haplodiploidy hypothesis although inequality (1) can still be achieved by $n_{i}$ being appropriately greater than $n_{o}$. Indeed there is no need to measure levels of genetic relatedness at all if any value of $r_{i}$, however low, is considered consistent with the hypothesis because inequality (1) can always be achieved by. $n_{i}>n_{o}$. Much ambiguity will be eliminated if the terms kin selection and haplodiploidy hypothesis are not used interchangeably. Kin selection is validated as long as inequality (1) is achieved, for whatever reason. Thus low values of $r_{i}$ by themselves pose no problem for general kin selection theory. I believe that testing the prediction as stated here is a necessary step towards understanding the role of haplodiploidy in selecting for worker behaviour. Besides, $r_{i}$ and $r_{o}$ are known or can be inferred for a large number of species while $n_{i}$ and $n_{o}$ remain as yet unknown for nearly all species (but see Queller and Strassmann 1989). This is not to deny the importance of environmental factors but to test the role of what can be measured precisely today (genetic relatedness, $r_{i}$ and $r_{o}$ ) by not mixing it up with what cannot be measured precisely today (differential productivities in the social and solitary modes, $n_{i}$ and $n_{o}$ ).

\subsection{Conceptual difficulties 2 and 3: What to do about males and what value of} relatedness is sufficient?

Males are peripheral to the social organisation of all Hymenopteran societies. Colonies consist principally of queens and workers, both of whom are females. Males may leave their natal nests soon after eclosion and lead a solitary life or may remain on their natal nests but take virtually no part in its social organisation. Because of the requirement of large worker forces (who are all females), most colonies usually consist of many more females than males, even if the latter remain on their natal nests. For these reasons most estimates of intra-colony genetic relatedness are for the females. Genetic relatedness to males is usually unknown as is the proportion of males in the brood. This poses a serious problem in estimating the average genetic relatedness between workers and the brood they rear. It is to be expected however that the inclusion of males is likely to lower the average workerbrood genetic relatedness because males among the brood are most likely to be brothers of the workers and therefore related to them by a coefficient of genetic relatedness of a mere $0 \cdot 25$.

The question of what value of relatedness is sufficient is perhaps the most serious conceptual difficulty in testing the haplodiploidy hypothesis.' When intra-colony 
relatedness among females approaches 0.75 , it is often considered favourable to Hamilton's ideas (e.g. Ross and Fletcher 1985, Ross and Matthews 1989a,b) and when it falls below 0.5, it is often considered unfavourable (e.g. Ward 1983, Ross 1986, Queller et al. 1988). It is clear that a value as high as 0.75 is not strictly necessary and a value below 0.5 will not do. But what, then, is the threshold value?

Workers will get no more fitness than solitary foundresses if they do not skew investment in favour of sisters over brothers. This is because, when they rear equal mixtures of full-sisters and brothers, their average relatedness to the brood will be 0.5. A combination of Fisher's sex ratio theory (Fisher 1930) and Hamilton's kin selection theory (Hamilton 1964a, b) shows that if workers control investment, they would be selected to achieve a ratio of investment between female and male brood in the ratio of their genetic relatedness to the two classes of brood (Trivers and Hare 1976; Oster et al. 1977; Macnair 1978; Craig 1980; Uyenoyama and Bengtsson 1981; Charnov 1978, 1982; Joshi and Gadagkar 1985).

There is admittedly some controversy about whether workers control investment and whether they are actually able to achieve the optimum ratio of investment. In order to be able to perform a test of the haplodiploidy hypothesis, however, I will assume that workers are capable of skewing investment in their brothers and sisters in the ratio of their relatedness to them. This assumption may somewhat bias my test in favour of haplodiploidy but it will at least permit an objective test under a set of well-defined assumptions. Besides, a falsification of the haplodiploidy hypothesis in spite of a bias in its favour would be more convincing than that of one which contains a bias against it.

Consider an outbred population where the queens are singly mated and workers rear full-sisters and brothers by successfully investing in their sisters and brothers in the ratio of their relatedness to them (3:1 in favour of sisters) (Trivers and Hare 1976). The weighted mean relatedness between workers and the brood they rear will be $[(0.75 \times 3)+(0.25 \times 1)] / 4=0.625$. This value is greater than 0.5 which is the mean relatedness between a solitary female and her offspring. Under these conditions worker behaviour will be favoured. Clearly, workers have an advantage over solitary females even if the weighted mean relatedness between the workers and the brood they rear is less than 0.625 but greater that 0.5 . The problem then is to find that value of relatedness between workers and their sisters which will make the weighted mean relatedness to their brood equal to 0.5 . In other words, given that workers are investing in their brothers and sisters in the ratio of their relatedness to them and that they are contributing as many individuals to the next generation as the solitary foundress $\left(n_{i}=n_{0}\right)$, what is the average degree of relatedness between a worker and her sisters above which helping will pay and below which it will not?

If $r_{f}$ is the mean genetic relatedness between workers in a Hymenopteran colony and their sisters, the optimum number of sisters that they shocld rear relative to every brother reared is given by:

$$
r_{f} / 0 \cdot 25 \text {, }
$$

where 0.25 is the expected mean genetic relatedness between the workers and their brothers (Charnov 1982, p. 126). Of course workers may sometimes produce some male offspring of their own. This and other factors that may alter worker-male brood genetic relatedness are dealt with below, in $\S 6$. When workers successfully skew investment between sisters and brothers in the ratio $r_{f} / 0 \cdot 25: 1$, their weighted 
mean genetic relatedness to siblings is given by:

$$
\bar{r}=\left[\left(r_{f}^{2} / 0 \cdot 25\right)+0 \cdot 25\right] /\left[\left(r_{f} / 0 \cdot 25\right)+1\right],
$$

where 0.25 is the expected genetic relatedness between workers and their brothers and $\bar{r}$ is the weighted mean genetic relatedness to the brood they rear. Equation (3) needs to be solved for $\bar{r}=0.5$ and may be rewritten as

$$
\left[\left(\hat{r}_{f}^{2} / 0 \cdot 25\right)+0 \cdot 25\right] /\left[\left(\hat{r}_{f} / 0 \cdot 25\right)+1\right]=0 \cdot 5,
$$

where $\hat{r}_{f}$ is the threshold relatedness between workers and their sisters which gives a weighted mean relatedness of 0.5 between workers and the brood they rear, provided workers can skew investment in their sisters and brothers in the ratio of their relatedness to them. Equation (4) may be rewritten as

$$
16 \hat{r}_{f}^{2}-8 \hat{r}_{f}-1=0
$$

and yields a value of 0.604 for $\hat{r}_{f}$. This means that a minimum genetic relatedness of 0.604 between workers and their sisters is required if workers are to gain at least as much fitness as solitary individuals, in spite of skewing investment between sisters and brothers in the ratio of their relatedness to them. I will call this number, $\hat{r}_{f}=0.604$, as the haplodiploidy threshold. The haplodiploidy threshold is thus that value of genetic relatedness between workers and the female brood they rear so that, upon skewing investment between sisters and brothers in the ratio of their relatedness to them, their weighted mean relatedness to the brood they rear is equal to 0.5 , the value expected for solitary individuals (Gadagkar 1990b). The haplodiploidy threshold thus simultaneously provides solutions to conceptual difficulties 2 and 3 , namely, what to do about males and what value of genetic relatedness is sufficient? Note that I have defined the haplodiploidy threshold in terms of the relatedness required between workers and their sisters merely because data on genetic relatedness between sisters are most readily available and need to be evaluated. I also show the derivation of the haplodiploidy threshold graphically in figure 1.

\subsection{Conceptual difficulty 4: How to deal with primitively eusocial and highly eusocial species?}

There is considerable ambiguity in the literature about whether or not to interpret low intra-colony relatedness in highly eusocial species (those with morphological castes) as evidence against the role of genetic asymmetries created by haplodiploidy in social evolution. The reason for this ambiguity is that one can always argue that highly eusocial species with morphologically specialised castes have been locked into sociality and the workers, having no way of obtaining any direct fitness, will be selected to work even if their inclusive fitness is significantly lower than would be expected for a solitary individual.

True, one may argue that worker-brood relatedness in highly eusocial species need not be high because workers have no direct reproductive options and that, being locked into sociality, they cannot revert to a solitary life. However, the example of the. Cape Honey Bee shows that even in a highly eusocial species, workers can potentially regain reproductive capacity (Anderson 1963; Moritz 1986, 1989). I therefore propose that the question we should be asking with highly 


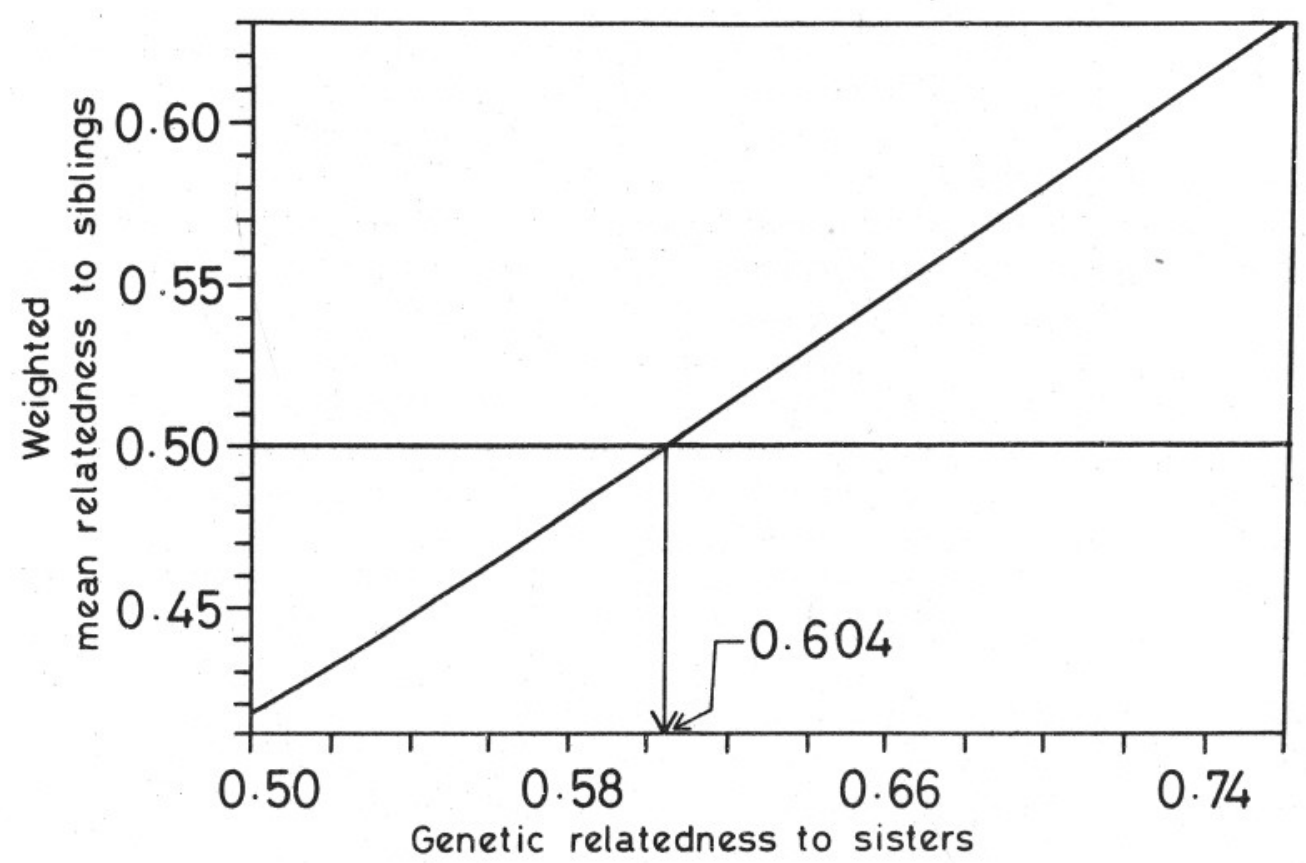

Figure 1. A graphic illustration of the haplodiploidy threshold. Workers are assumed to be capable of skewing investment between their sisters and brothers in their ratio of relatedness to them. Assuming that workers are related to their brothers by $0 \cdot 25$, I plot the weighted mean relatedness to siblings obtained for different values of relatedness to sisters. The haplodiploidy threshold is that value of relatedness to sisters that yields a weighted mean relatedness to siblings of 0.5 so that workers break even with solitary foundresses. In an outbred population, the haplodiploidy threshold is equal to 0.604 .

eusocial species is whether genetic asymmetries created by haplodiploidy are responsible for the maintenance of eusociality. In other words, is the mean workerbrood relatedness higher than expected for a solitary individual so that it can act as a barrier for workers to revert to a reproductive or solitary state? So long as we show that genetic asymmetries created by haplodiploidy are not sufficient to select for a mutant that reverts back to the reproductive or solitary state, it is a satisfactory falsification of the haplodiploidy hypothesis. I will therefore use data on highly eusocial species to test the hypothesis that asymmetries created by haplodiploidy alone are sufficient to maintain the eusocial state.

In most primitively eusocial species, workers are capable of mating and reproducing and often have opportunities to leave their nests and initiate their own solitary foundress nests. The problem of why most individuals under these circumstances accept sterile worker roles may be thought of as the problem of the origin of eusociality as opposed to its maintenance. I will therefore use data on primitively eusocial species to ask if the genetic asymmetries created by haplodiploidy are sufficient to promote the origin of eusociality. In other words, are workers in primitively eusocial species accepting sterility merely because they have an opportunity to rear brood that is more closely related to them than their own offspring would be? 
sisters for them to obtain the same mean relatedness to brood as is expected for solitary individuals and given several estimates of intra-colony genetic relatedness among females, there still remains the question of what constitutes a test of the haplodiploidy hypothesis.

In appendix 1, I list 185 published estimates of intra-colony genetic relatedness in various species of social Hymenoptera. These estimates are of genetic relatedness among the workers of a colony, among female alates eclosing from a colony, among the daughters in a colony, among female nestmates of a colony, among female foundresses of a colony and, in four cases, refer to relatedness between workers and the female brood they rear. All of these estimates pertain to relatedness between sisters and I will therefore use these estimates as approximations of the genetic relatedness between workers and the female reproductive brood they rear. Most estimates of genetic relatedness are accompanied by estimates of standard errors. I have therefore computed the $95 \%$ confidence limits of the relatedness values as mean $\pm 1.96 \times$ SE.

While a single estimate is available for some species, a number of estimates are available for others. The estimates for different loci, from different populations and those obtained by different methods of averaging, are all given. However, a single overall or consensus estimate with mean and standard error is not available for many of the latter species. This makes the use of these estimates in evaluating the role of haplodiploidy difficult. But, for the present, I will use all values that have been provided in the literature and draw what conclusions I can.

I will use four methods in my attempt to evaluate the published estimates of relatedness. (a) First, I will examine the distribution of the mean values of relatedness. (b) Second, I will use the $95 \%$ confidence intervals computed from the mean and the standard error and count the number of estimates significantly less than the haplodiploidy threshold of 0.604 (those whose upper confidence limit is less than the threshold), the number indistinguishable from the haplodiploidy threshold (those whose confidence intervals overlap with the threshold) and the number that are significantly higher than the haplodiploidy threshold (those whose lower confidence limits are higher than the threshold). The level of statistical significance here corresponds to $p<0.025$ as I am using the $95 \%$ confidence limits but I am interested in a one-tailed test. Here, I will consider the estimates significantly lower than the threshold as providing evidence against the role of haplodiploidy, the estimates significantly higher than the threshold as providing evidence for the role of haplodiploidy and the estimates overlapping with the threshold as being incapable of providing evidence one way or the other. (c) Third, to correct for the problem of multiple estimates per species in a small way, I will count the number of species that have at least one estimate significantly higher than the threshold and treat this as strong evidence in support of the role of haplodiploidy. Conversely, I will treat the absence of even a single estimate (when more than one is available) being significantly higher than the threshold as strong evidence against the role of haplodiploidy. (d) Fourth, I will use the normal approximation to compute the probability that a randomly picked value from the observed distribution is above the threshold by computing the area under the curve that is above the threshold. I will then examine the distribution of such probability values. In each case, I shall first consider all species simultaneously and then separately deal with highly eusocial and primitively eusocial species. 


\section{A test of the haplodiploidy hypothesis}

\subsection{Distribution of mean relatedness values}

In figure $2 \mathrm{~A}$ I have plotted the frequency distribution of the 185 mean values of genetic relatedness from appendix 1 and from figure 3 (below). This distribution has a mean of 0.50 and a median of 0.57 . These values are strikingly lower than 0.75 , the expected genetic relatedness among full-sisters in the Hymenoptera. Low as they are, even these values are overestimates. This is because a single species, Microstigmus comes, which has consistently high values of intra-colony genetic relatedness is represented by 42 estimates whereas many other species which have low values of intra-colony relatedness are represented by one or a small number of estimates. In figure 2B I plot the resultant distribution after replacing the 42 estimates for $M$. comes with a single consensus estimate of 0.63 (Ross and Matthews 1989 b). This distribution has a mean of 0.45 and a median of 0.48 . The 90 estimates for highly eusocial species are even lower with a mean of 0.37 and a median of 0.30 (figure 2C). The remaining 95 estimates for primitively eusocial species appear, at first sight, to be high, with a mean of 0.62 and a median of 0.64 (figure 2D). But this again is due to those 42 estimates for $M$. comes! When replaced with the single consensus estimate, the distribution for primitively eusocial species also appears to be far below expectation with a mean of 0.58 , a standard deviation of 0.15 and a median of 0.57 (figure 2E). One solution to the problem of multiple estimates per species is to take the arithmetic mean of all values for a species and examine the distribution of these means. When all species are taken together, this distribution has a mean of 0.4279 , a standard deviation of 0.1963 and a median of 0.387 . For highly eusocial species, the corresponding values are $0.3422,0.1952$ and 0.316 , and similarly for primitively eusocial species, $0.5316,0.1395$ and 0.539 . We may therefore conclude from this survey of the distribution of mean values of genetic relatedness that the expected value of 0.75 is rarely achieved and that the genetic asymmetry potentially created by haplodiploidy is broken down to a considerable extent. This appears to be the case both for highly eusocial and primitively eusocial species although the values for primitively eusocial species are considerably higher than those for highly eusocial species.

5.2 Estimates significantly lower, overlapping with, and significantly higher than the haplodiploidy threshold

Eight of the 185 estimates of genetic relatedness listed in the appendix 1 are without standard errors and I cannot therefore use them in the following three methods of evaluation. Of the remaining 177 estimates, 49 are significantly lower than the haplodiploidy threshold and thus provide evidence against the role of haplodiploidy (figure 3 and table 1). Of these, 31 pertain to ants, 2 to vespine wasps, 10 to swarmfounding wasps, 3 to primitively eusocial bees and 3 to primitively eusocial wasps. 106 estimates do not provide evidence one way or the other because they overlap with the haplodiploidy threshold. Only 22 estimates are significantly higher than the haplodiploidy threshold. Of these, 5 pertain to ants, none to vespine wasps and swarm-founding wasps, 4 to primitively eusocial bees and 13 to primitively eusocial wasps. Taken together these numbers can by no means be said to provide strong 


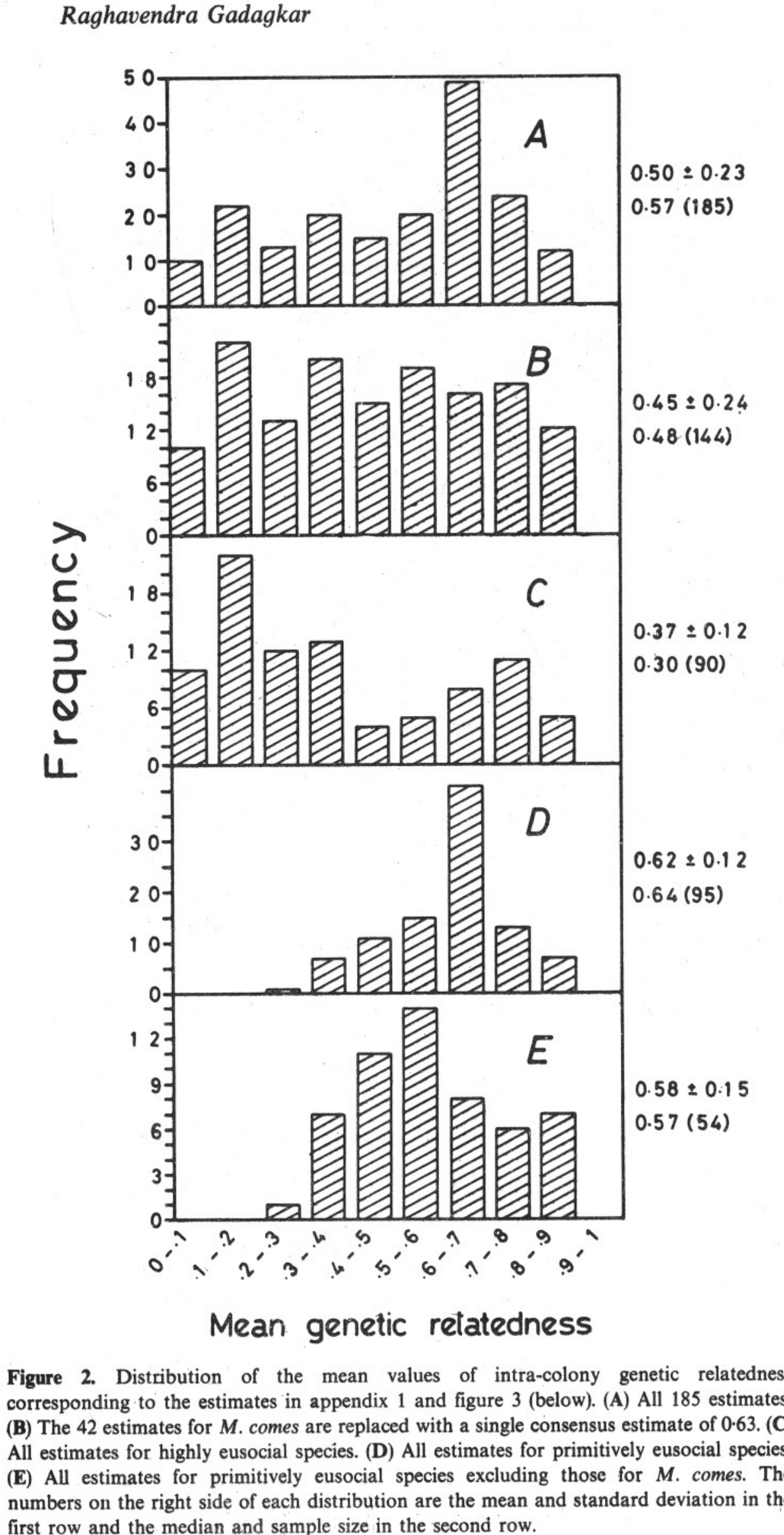


support for the role of haplodiploidy either in the origin or the maintenance of eusociality in the Hymenoptera.

\subsection{Species that have at least one estimate significantly higher than the haplodiploidy threshold}

Since there are often several estimates for a given species, I will now count species rather than estimates (table 1). Of the 15 species of ants that have estimates with standard errors, only 3 have at least one estimate which is significantly higher than the haplodiploidy threshold. These are Solenopsis geminata for which 3 out of 5 estimates are significantly higher than the threshold, Solenopsis invicta for which 1 out of the 4 estimates is significantly higher and Solenopsis richteri for which the only estimate available is significantly higher than the haplodiploidy threshold. The single species of honey bee does not have an estimate with standard error but it is expected to have a value close to $0 \cdot 25$. The 2 species of vespine wasps do not have values significantly higher than the haplodiploidy threshold. Of the 3 species of swarm-founding wasps studied, none has even one estimate which is significantly higher than the haplodiploidy threshold. Thus out of 20 species of highly eusocial Hymenopterans studied, only 3 have at least one estimate higher than the haplodiploidy threshold. These results suggest that the genetic asymmetry created by haplodiploidy by itself cannot maintain the eusocial state in most highly eusocial Hymenoptera. In other words, barring a few exceptions, workers in highly eusocial Hymenoptera are not prevented from reverting to the solitary state merely because they are rearing brood more closely related to them than solitary individuals would do. Clearly, there must be other forces which prevent such species from turning solitary.

Of the 2 primitively eusocial bees studied, Lasioglossum zephyrum has only 4 out of 26 estimates significantly higher than the haplodiploidy threshold. It should also be noted that all four estimates which are significantly higher than the haplodiploidy threshold are from Kansas; none from New York is significantly higher. Of the 8 estimates available for the other primitively eusocial bee, Exoneura bicolor, none is significantly higher than the haplodiploidy threshold. Of the 17 species of primitively eusocial wasps studied, only 2 have estimates higher than the haplodiploidy threshold. One is Microstigmus comes in which only 12 out of 42 estimates are higher than the haplodiploidy threshold. The other is Mischocyttarus immarginatus in which the only estimate available is higher than the haplodiploidy threshold. Thus, out of 13 species of primitively eusocial Hymenopterans which have estimates of intra-colony genetic relatedness with standard errors, only 3 have at least one estimate significantly higher than the haplodiploidy threshold although it must be mentioned that most species of primitively eusocial wasps have only one or two estimates. It seems reasonable to conclude from these numbers that the genetic asymmetry potentially created by haplodiploidy cannot by itself promote the origin of eusociality either. In other words, even in species where workers have reproductive options, barring a few exceptions, they do not appear to assume worker roles and behave altruistically merely because they are rearing brood to whom they are more closely related than a solitary female is to her brood. Clearly, there must be other factors which select for such worker behaviour.

An important assumption made in performing this test of the haplodiploidy hypothesis is that workers can skew investment in their sisters and brothers in the 
Vespine wasps Honey bee

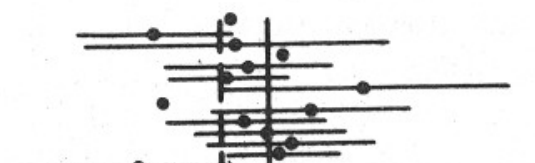

Primitively eusocial wasps

Primitively eusocial bees
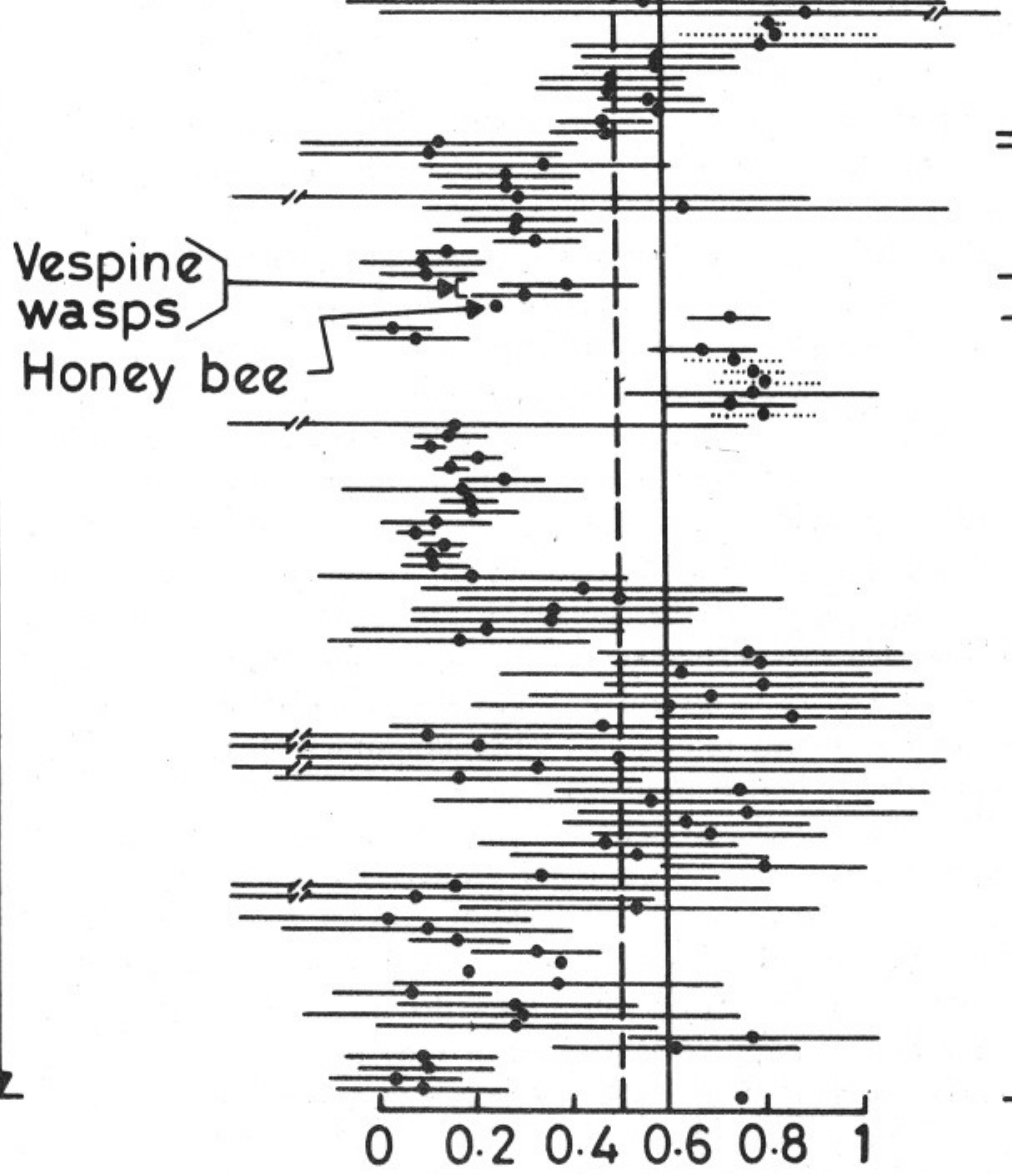

Ants

Genetic relatedness

Figure 3. (Caption on facing page.) 
Table 1. A test of the haplodiploidy hypothesis using the threshold of $0 \cdot 604$-Summary.

\begin{tabular}{|c|c|c|c|c|c|c|c|}
\hline Group & $\begin{array}{c}\text { No. of } \\
\text { estimates } \\
\text { available }\end{array}$ & $\begin{array}{l}\text { No. of } \\
\text { estimates } \\
\text { without } \\
\text { standard } \\
\text { error }\end{array}$ & $\begin{array}{l}\text { No. of esti- } \\
\text { mates signifi- } \\
\text { cantly low- } \\
\text { er than the } \\
\text { haplodiploidy } \\
\text { threshold }\end{array}$ & $\begin{array}{c}\text { No. of } \\
\text { estimates } \\
\text { overlapping } \\
\text { with the } \\
\text { haplodiploidy } \\
\text { threshold }\end{array}$ & $\begin{array}{l}\text { No. of esti- } \\
\text { mates signi- } \\
\text { ficantly grea- } \\
\text { ter than the } \\
\text { haplodiploidy } \\
\text { threshold }\end{array}$ & $\begin{array}{c}\text { No. of species } \\
\text { for which } \\
\text { estimates } \\
\text { with } \\
\text { standard } \\
\text { errors are } \\
\text { available }\end{array}$ & $\begin{array}{l}\text { No. of species } \\
\text { for which at } \\
\text { least one esti- } \\
\text { mate is signi- } \\
\text { ficantly gre- } \\
\text { ater than the } \\
\text { haplodiploidy } \\
\text { threshold }\end{array}$ \\
\hline Ants & 74 & 3 & 31 & 35 & 5 & 15 & 3 \\
\hline Honey bee & 1 & 1 & 0 & 0 & 0 & 0 & 0 \\
\hline $\begin{array}{l}\text { Vespine } \\
\text { wasps }\end{array}$ & 2 & 0 & 2 & 0 & 0 & 2 & 0 \\
\hline $\begin{array}{l}\text { Swarm- } \\
\text { founding } \\
\text { wasps }\end{array}$ & 13 & 0 & 10 & 3 & 0 & 3 & 0 \\
\hline $\begin{array}{l}\text { Primitively } \\
\text { eusocial } \\
\text { bees }\end{array}$ & 34 & 0 & 3 & 27 . & 4 & 2 & 1 \\
\hline $\begin{array}{l}\text { Primitively } \\
\text { eusocial } \\
\text { wasps }\end{array}$ & 61 & 4 & 3 & 41 & 13 & 13 & 2 \\
\hline Total & 185 & 8 & 49 & 106 & 22 & 35 & 6 \\
\hline
\end{tabular}

ratio of their relatedness to them. Haplodiploidy cannot select for worker behaviour if workers are incapable of effecting this bias. Our conclusion that haplodiploidy by itself cannot promote the origin or maintenance of eusociality thus remains valid even if this assumption does not hold. If workers invest equally in brothers and sisters, their weighted average relatedness to brood will be 0.5 and thus $r_{i}=r_{o}$. It is however possible that workers can skew investment only partially and thus somewhat less than what is optimal for them. For instance, Boomsma (1989) has argued that female bias in sex-investment ratios has been systematically overestimated and that, in monogynous ants, it is only about $1.82: 1$ rather than the expected $3: 1$. When such values for investment ratios are used, the haplodiploidy threshold goes up. For instance, the haplodiploidy threshold would go up to 0.638 and only 9 instead of 22 out of 177 values would be significantly greater than the threshold if I were to use the female-to-male investment ratio of 1.82:1 after Boomsma (1989). Similarly, one could use the investment ratio empirically determined for the primitively eusocial wasp Microstigmus comes (Ross and Matthews 1989b). The only problem here is that the estimated female-to-male investment ratio is a conservative approximation based on several assumptions which "...should be regarded as a minimum value for the extert of female-biased investment" (Ross and Matthews 1989b, p. 587). If I were to use the value of $1 \cdot 78: 1$ (females:males) estimated by them and use their consensus estimate of 0.63 for

Figure 3. A test of the haplodiploidy hypothesis. 185 estimates of genetic relatedness between sisters in Hymenopteran colonies are shown. The dots are the mean values and the bars indicate $95 \%$ confidence limits. In 8 cases, only the means are shown as there are no estimates of standard errors. The vertical solid line is the haplodiploidy threshold $(0 \cdot 604)$. All estimates that are significantly greater than the haplodiploidy threshold and thus lie entirely to the right of the vertical line are shown by dotted lines. For comparison I have shown a vertical broken line corresponding to a threshold of 0.5 . 
relatedness to sisters and $0 \cdot 21$, the higher of their two estimates, for relatedness to brothers, the weighted mean relatedness to siblings would be only 0.479 . If these values are accurate, haplodiploidy alone cannot select for worker behaviour even in M. comes.

\subsection{Probability of relatedness value being above the haplodiploidy threshold}

As mentioned in $\S 4.4$, I use the normal approximation to compute for each estimate the area under the curve that is above the haplodiploidy threshold and interpret it as the probability that the relatedness is greater than the threshold. In figure 4A, I plot the distribution of such probability values for the 177 estimates for which standard errors are available. This is a clearly bimodal distribution with a mean of 0.46 and a median of 0.45 . This means that for more than half the estimates, the probability of being above the haplodiploidy threshold is less than 0.5 . Even so, this value is an overestimate because of the inclusion of a large number of high values for the single species $M$. comes. This time I cannot replace the 42 values for this species with the consensus estimate because the consensus estimate has no standard error associated with it. If I simply delete the 42 values for $M$. comes the resultant distribution has a mean of 0.33 and a median of $0 \cdot 13$. Indeed, for nearly half the estimates, the probability of being above the haplodiploidy threshold is 0.13 or less (figure 4B). As in the previous methods, separating out highly eusocial and primitively eusocial species yields similar results. The values for the highly eusocial species have a mean probability of being above the haplodiploidy threshold of 0.26 and a median probability of 0.02 (figure 4C). This means that for half the estimates, the probability of being above the haplodiploidy threshold is less than 0.02 . The probability values appear high for primitively eusocial species (figure $4 \mathrm{D}$; mean $\pm \mathrm{SD}=0.64 \pm 0.34$, median $=0.74$ ). But this again is due to the large number of values for $M$. comes. Upon deleting these we have a mean of 0.44 and a median of 0.43 (figure 4E). This means that even for primitively eusocial species the probability of being above the haplodiploidy threshold is less than half for more than half the estimates. Taken together, these numbers once again fail to provide strong support for the role of haplodiploidy and in fact suggest that for most species, most of the time, workers are not being selected to be altruistic because of higher genetic relatedness to the brood they rear compared to what they may have obtained if they had been solitary individuals.

\section{The effects of polygyny and worker reproduction}

Workers in Hymenopteran colonies sometimes lay their own haploid eggs instead of, or in addition to, rearing the queen's haploid male offspring (Fletcher and Ross 1985; Bourke 1988). This may increase relatedness between a worker and the male brood on the nest $(r=0.5$ if she lays the haploid eggs and $r=0.375$ if the haploid eggs are laid by other workers who may be her full-sisters). Worker reproduction may also decrease relatedness to male brood if the haploid eggs are laid by their half-sisters $(r=0.125)$. Polygyny (either the simultaneous egg-laying by more than one female or frequent queen replacements) leads to considerable reduction in genetic relatedness between workers and the brood they rear. There is evidence in the primitively eusocial wasp $R$. marginata that workers rear brood which may be 


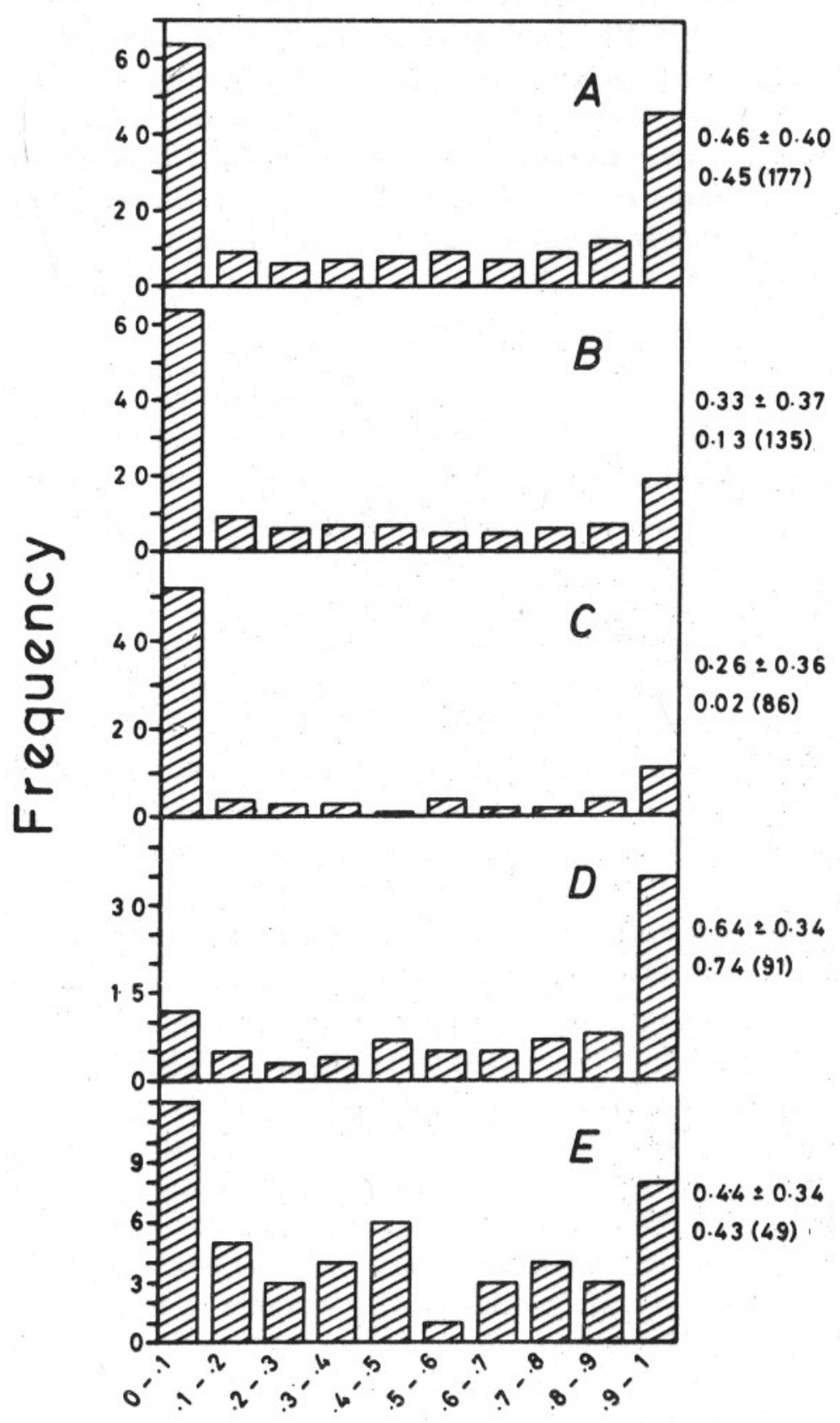

Prob. of being above threshold

Figure 4. Probability of relatedness estimates being higher than the haplodiploidy threshold of 0.604 . Using the normal approximation, the area under the curve which is above the haplodiploidy threshold of 0.604 has been computed for each estimate using its mean and standard error shown in figure 3 and appendix 1 . This area is interpreted as the probability that a randomily picked value from the distribution will be higher than the haplodiploidy threshold. The distribution of such probability values is shown here. (A) All 177 estimates. (B) All estimates excluding those for $M$. comes. (C) All estimates for highly eusocial species. (D) All estimates for primitively eusocial species. (E) All estimates for primitively eusocial species excluding those for $M$. comes. 
complex mixtures of their full-sisters, half-sisters, brothers, nieces, nephews and cousins and sometimes rear brood as distantly related to them as their mother's halfsister's offspring $(r=0.0625)$ (Gadagkar et al. 1990; Gadagkar 1991). Let us therefore consider a more general situation where relatedness of workers to male brood can vary between 0 and 0.5 and that to female brood between 0 and 0.75 . Assuming once again that workers can skew investment between the female and male brood in the ratio of their relatedness to them, the equation required to calculate the haplodiploidy threshoid can now be written as

$$
\bar{r}=\left[\left(r_{f}^{2} / r_{m}\right)+r_{m}\right] /\left[\left(r_{f} / r_{m}\right)+1\right],
$$

where $r_{f}$ is the genetic relatedness between workers and the female brood, $r_{m}$ is the genetic relatedness between workers and the male brood and $\bar{r}$ is the weighted mean relatedness to brood. I thus compute (numerically) pairs of values of relatedness of workers to female and male brood where the weighted mean relatedness to brood (if they invest in the ratio of their relatedness to them, i.e., $\left.r_{f} / r_{m}: 1\right)$, is equal to or greater than 0.5 . The results of this are shown in figure 5 where the unhatched region represents the set of values where haplodiploidy by itself cannot select for worker behaviour $(\bar{r} \leqslant 0.5)$ and the hatched region represents the set of values where it can $(\bar{r}>0.5)$. There are three main points of interest in this figure.

(1) All regions where relatedness to female brood is greater than 0.75 and that to male brood is greater than 0.5 , are considered not allowed because these values are unlikely to be obtained except through inbreeding. The region where haplodiploidy will select for worker behaviour is small and represents only about $24 \%$ of the allowed relatedness space (i.e., where relatedness to female brood is between 0 and 0.75 and that to male brood is between 0 and 0.5 ).

(2) There-is a small region where the haplodiploidy threshold is less than 0.604 (the hatched region to the left of the dotted line in figure 5). This is because, by rearing mixtures of sons and sisters, workers can gain relatively more fitness than they would by rearing mixtures of brothers and sisters. Production of a colony's male offspring by workers should therefore promote social evolution by haplodiploidy. This may appear to invalidate the test of the haplodiploidy hypothesis performed in $\S 5$. There are, however, at least three reasons why the test may still be valid. First, there is little evidence of male production by workers in the species used here to test the haplodiploidy hypothesis. Second, recent theoretical work indicates that the efforts of workers to lay eggs are unlikely to succeed because, when queens mate multiply (as they often do), workers cannot "agree" on which one of them should lay the eggs. This is expected to lead to worker policing that results in the destruction of worker-laid eggs (Ratnieks 1988). Observations on the honeybee Apis mellifera show that such theoretical expectations are borne out (Ratnieks and Visscher 1989; Visscher 1989). Third, the haplodiploidy threshold is only marginally lowered for moderate levels of male production by workers. The value of 0.604 when workers lay no eggs reduces only to 0.601 when workers produce $20 \%$ of a colony's haploid eggs and only to 0.582 when workers lay $50 \%$ of a colony's haploid eggs (figure 6). My test of the haplodiploidy hypothesis thus appears to be quite robust.

(3) The third point of interest in figure 5 is the rather unexpected region, shown by the double-headed arrow. When relatedness to female brood is 0.55 and that to 


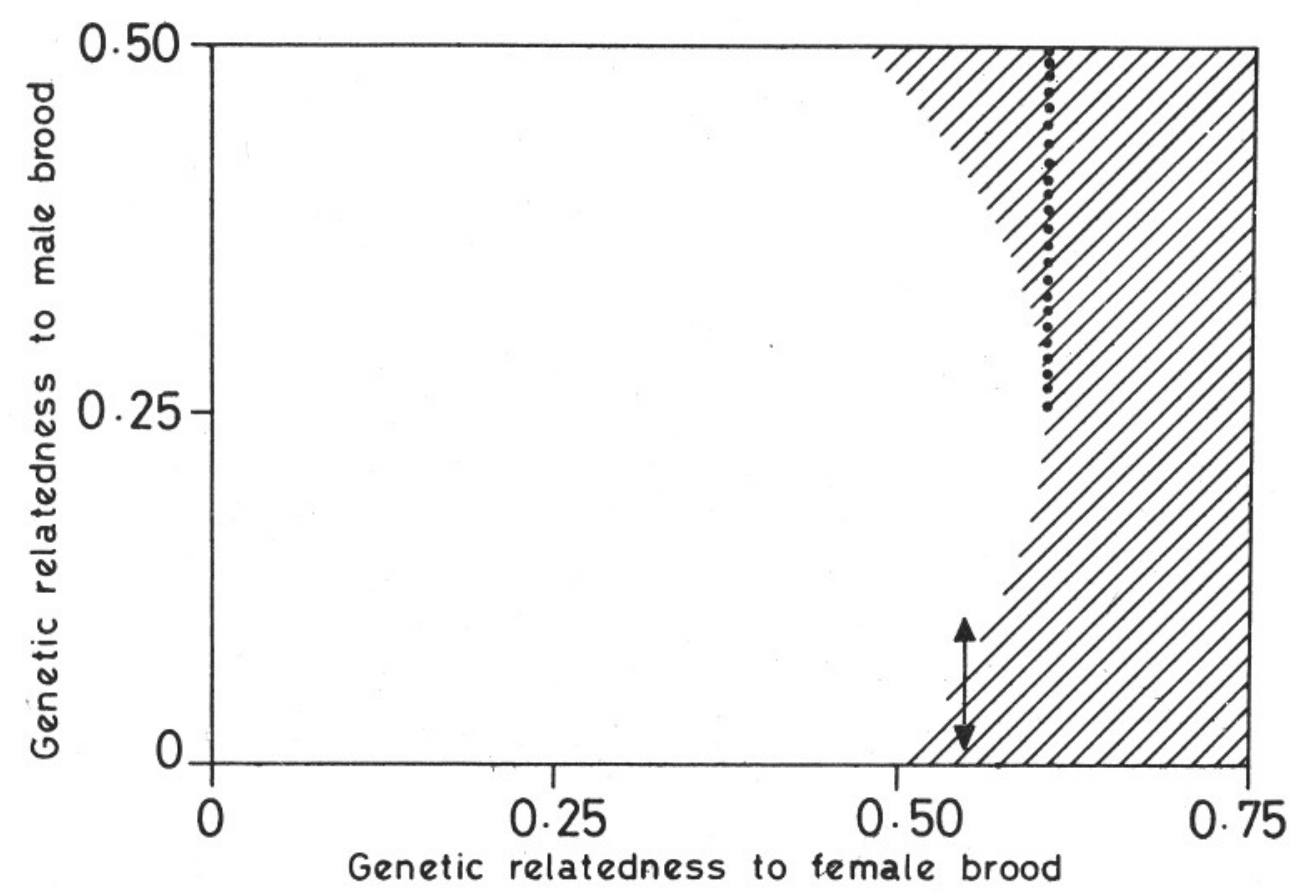

Figure 5. Regions in the relatedness space where haplodiploidy by itself can select for worker behaviour. Assuming that workers can skew investment between male and female brood in the ratio of their relatedness to them, the resultant weighted mean relatedness to brood $\bar{r}$ is computed from (6). When $\bar{r}>0.5$, workers gain more fitness than solitary foundresses and therefore haplodiploidy by itself can select for worker behaviour (hatched region). The unhatched region is that where haplodiploidy by itself cannot select for worker behaviour because $\bar{r} \leqslant 0.5$. Note that in an outbred population, relatedness to male brood is not likely to be greater than 0.5 (sons) and to female brood is not likely to be greater than 0.75 (full-sisters). The region where haplodiploidy can select for worker behaviour is therefore restricted to the small hatched region which corresponds to about $24 \%$ of the allowed relatedness space. The hatched region to the left of the dotted line is where the haplodiploidy threshold is less than 0.604 because workers are assumed to rear sons instead of, or in addition, to some brothers. The region shown by the double-headed arrow illustrates that a simple mean of relatedness to male and female brood does not always predict the consequences for social evolution. For example, when relatedness to female brood is 0.55 and that to male brood is 0.05 (lower arrow-head), haplodiploidy will select for worker behaviour. If relatedness to female brood remains at 0.55 , but that to male brood is increased to 0.1 (upper arrow-head), haplodiploidy will no longer select for worker behaviour (see also table 2).

male brood is 0.05 , the simple average relatedness to brood is 0.3 . But the optimum sex-investment ratio from the point of view of workers is 11:1 (in favour of female brood) and this gives a weighted mean relatedness of 0.508 when haplodiploidy will select for worker behaviour. When relatedness to female brood remains at 0.55 but that to male brood is increased to $0 \cdot 1$, the simple average relatedness to brood is 0.325 and thus higher than before. But the optimum sex-investment ratio now is $5.5: 1$ (computed from equation $r_{f} / r_{m}: 1$ in parenthesis on p. 16 , line 14) and the weighted mean relatedness to brood becomes $0 \cdot 480$ (from (6)). Consequently, haplodiploidy will no longer select for worker behaviour (see table 2). A simple mean of the relatedness to female and male brood is therefore not a good indicator of whether or not haplodiploidy can select for worker behaviour. 


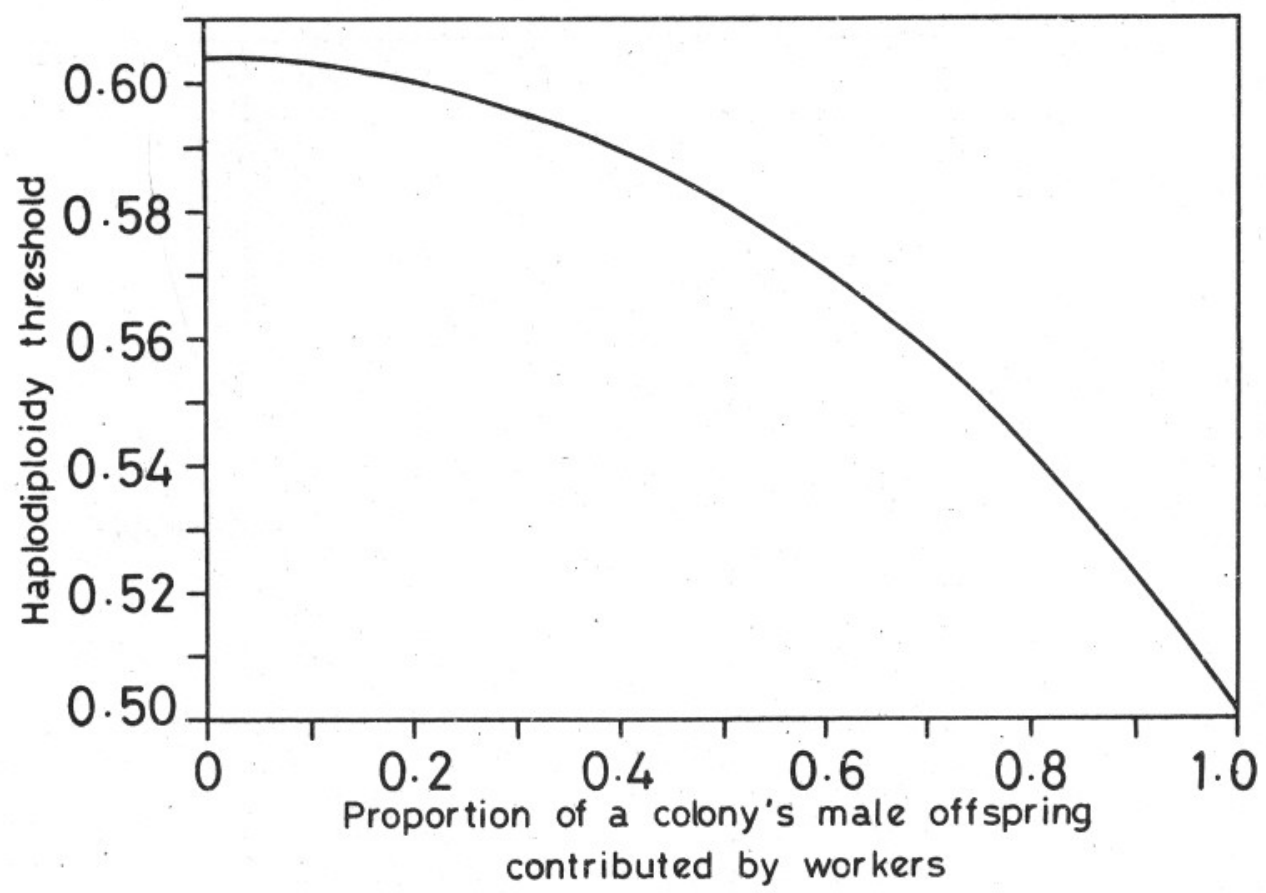

Figure 6. Effect of male production by workers on the haplodiploidy threshold. When a worker contributes a certain proportion of a colony's male offspring (by laying haploid eggs), the weighted mean relatedness between it and the colony's male brood is given by $[0.5 w+0.25(1-w)]$ where, $w$ is the proportion of a colony's male brood contributed by a worker and $(1-w)$ that contributed by the queen. For different values of $w$, the haplodiploidy threshold is now computed as in figure 3 by using the appropriate weighted mean relatedness to male brood in place of $r_{m}$. As expected, the haplodiploidy threshold decreases as the proportion of haploid eggs laid by a worker increases. However, for moderate levels of haploid egg production by workers, the reduction in the haplodiploidy threshold is marginal. When a worker lays $20 \%$ of a colony's haploid eggs, for example, the haplodiploidy threshold drops only to 0.601 and when it produces $50 \%$ of a colony's haploid eggs, the haplodiploidy threshold drops only to 0.582 . For simplicity, I have not considered the effect of haploid eggs laid by other workers on the fitness of a given worker. Besides, that is likely to have less effect than its own haploid egg production.

\section{A threshold of 0.5 ?}

Two arguments may possibly be made against my method of computation of the haplodiploidy threshold. These arguments are different for the origin and for the maintenance of eusociality and both suggest a threshold of 0.5 instead of 0.604 . As I have already emphasized, the most important assumption in my analysis is that workers are capable of biasing investment in the ratio of their genetic relatedness to brood. During the origin of eusociality, however, it may be argued that workers may be selected to rear an all-female brood. If this happens of course any value of relatedness among sisters greater than 0.5 is sufficient to select for worker behaviour. During the maintenance of eusociality, if all individuals in the population are eusocial and if everybody produces the same female-biased sex-ratio, the value of males increases. In fact the life-for-life coefficients of genetic relatedness of Hamilton (1972) show that this is equivalent to an increased relatedness to males such that they become as related to the workers as female brood would be. This 
Table 2. An example to illustrate that a simple average of the relatedness to female and male brood does not always predict the consequences for social evolution through haplodiploidy.

\begin{tabular}{lcc}
\hline & Example 1 & Example 2 \\
\hline $\begin{array}{l}\text { Relatedness to } \\
\text { female brood }\end{array}$ & 0.55 & 0.55 \\
$\begin{array}{l}\text { Relatedness to } \\
\text { male brood }\end{array}$ & 0.05 & 0.10 \\
$\begin{array}{l}\text { Simple average } \\
\text { relatedness to } \\
\text { brood }\end{array}$ & 0.300 & 0.325 \\
$\begin{array}{l}\text { Expected female } \\
\text { to male sex ratio } \\
\text { based on ratio of } \\
\text { relatedness }\end{array}$ & $11: 1$ & $5.5: 1$ \\
$\begin{array}{l}\text { Weighted mean } \\
\text { relatedness to } \\
\text { brood }\end{array}$ & 0.508 & 0.480 \\
$\begin{array}{l}\text { Haplodiploidy } \\
\text { by itself can } \\
\text { select for } \\
\text { worker behaviour }\end{array}$ & Yes & \\
\hline
\end{tabular}

would again suggest that any relatedness among sisters greater than 0.5 will be sufficient to select for worker behaviour. Much depends therefore on what ratios of sex-biased investment will be possible and will be selected among incipient workers and among highly eusocial workers. Pending the resolution of this question, I will in the meantime, re-examine the data in appendix 1 using a threshold of 0.5 .

Now we have 38 of the 177 estimates significantly lower than 0.5 , which thus continue to provide evidence against haplodiploidy, 63 estimates significantly above 0.5 providing evidence in favour of haplodiploidy and 76 values overlapping with 0.5 (table 3). Of the 35 species studied, only 11 have at least one estimate which is significantly greater than the threshold $(0.5)$ (table 3 ). In figure $7 \mathrm{~A}$, I plot the distribution of the probabilities of being above 0.5 for the 177 estimates. In spite of using a threshold of 0.5 , the mean of this distribution is only 0.58 and the median is 0.74 . Moreover this again is an overestimate because of the inclusion of the 42 estimates for $M$. comes. On deleting these, the distribution has a mean of 0.45 and a median of 0.40 (figure 7B). This means that even if we use the threshold of 0.5 , the probability of being above the threshold $(0.5)$ is less than half for more than half the estimates. Separating out the highly eusocial and primitively eusocial species yields similar results as before. For the highly eusocial species the distribution has a mean of 0.33 and a median of 0.1 (figure 7C). For the primitively eusocial species the distribution has a mean of 0.82 and a median of 0.99 (figure 7D). But this is because of the $M$. comes estimates which are almost all significantly greater than 0.5 . Deleting them as before, yields a more modest mean of 0.66 and median of 0.75 (figure 7E). This still means that half the estimates for primitively eusocial species have a one in four chance of being less than 0.5 . I believe therefore that our conclusions have not changed in any major way by using a threshold of 0.5 rather 
Table 3. A test of the haplodiploidy hypothesis using the threshold of 0.5 -Summary.

\begin{tabular}{|c|c|c|c|c|c|c|c|}
\hline Group & $\begin{array}{c}\text { No. of } \\
\text { estimates } \\
\text { available }\end{array}$ & $\begin{array}{c}\text { No. of } \\
\text { estimates } \\
\text { without } \\
\text { standard } \\
\text { error }\end{array}$ & $\begin{array}{c}\text { No. of } \\
\text { estimates } \\
\text { significantly } \\
\text { lower } \\
\text { than the } \\
\text { threshold }\end{array}$ & $\begin{array}{c}\text { No. of } \\
\text { estimates } \\
\text { overlapping } \\
\text { with the } \\
\text { threshold }\end{array}$ & $\begin{array}{l}\text { No. of } \\
\text { estimates } \\
\text { significantly } \\
\text { greater } \\
\text { than the } \\
\text { threshold }\end{array}$ & $\begin{array}{c}\text { No. of } \\
\text { species for } \\
\text { which esti- } \\
\text { mates with } \\
\text { standard } \\
\text { errors are } \\
\text { available }\end{array}$ & $\begin{array}{l}\text { No. of } \\
\text { species for } \\
\text { which at } \\
\text { least one } \\
\text { estimate is } \\
\text { significantly } \\
\text { greater } \\
\text { than the } \\
\text { threshold }\end{array}$ \\
\hline Ants & 74 & 3 & 25 & 35 & 11 & 15 & 6 \\
\hline Honey bee & 1 & 1 & 0 & 0 & 0 & 0 & 0 \\
\hline $\begin{array}{l}\text { Vespine } \\
\text { wasps }\end{array}$ & 2 & 0 & 1 & 1 & 0 & 2 & 0 \\
\hline $\begin{array}{l}\text { Swarm- } \\
\text { Founding } \\
\text { wasps }\end{array}$ & 13 & 0 & 10 & 3 & 0 & 3 & 0 \\
\hline $\begin{array}{l}\text { Primitively } \\
\text { eusocial } \\
\text { bees }\end{array}$ & 34 & 0 & 1 & 26 & 7 & 2 & 1 \\
\hline $\begin{array}{l}\text { Primitively } \\
\text { eusocial } \\
\text { wasps }\end{array}$ & 61 & 4 & 1 & 11 & 45 & 13 & 4 \\
\hline Total & 185 & 8 & 38 & 76 & 63 & 35 & 11 \\
\hline
\end{tabular}

than one of 0.604 . The genetic asymmetry potentially created by haplodiploidy is insufficient by itself to promote the origin or the maintenance of eusociality.

\section{Conclusion}

A review of the literature shows that a fairly large number of estimates of intracolony genetic relatedness among females is available for social Hymenoptera. However, these estimates cannot at present be used very effectively because a number of different estimates per species are sometimes provided in the literature without a single summarising or consensus estimate with standard error. However the analysis presented here shows that a test of the role of genetic asymmetries created by haplodiploidy in selecting for worker behaviour in the Hymenoptera is possible provided some assumptions are made. The main assumption is that workers are capable of discriminating between male and female brood and skewing investment in proportion to their genetic relatedness to brood of the two sexes. A second asssumption is that of outbreeding which appears to be valid; no significant level of inbreeding has been reported in all but two of the populations studied. The main conclusion that emerges from this analysis is that the genetic asymmetry created by haplodiploidy by itself is unlikely to be responsible either for the origin or the maintenance of eusociality in the Hymenoptera. To the extent that relatively few populations of few species have been studied so far, the test of the haplodiploidy hypothesis presented here may be considered preliminary. However, as it becomes available, the methodology developed here can be readily used to incorporate new information concerning genetic relatedness and the ability or 


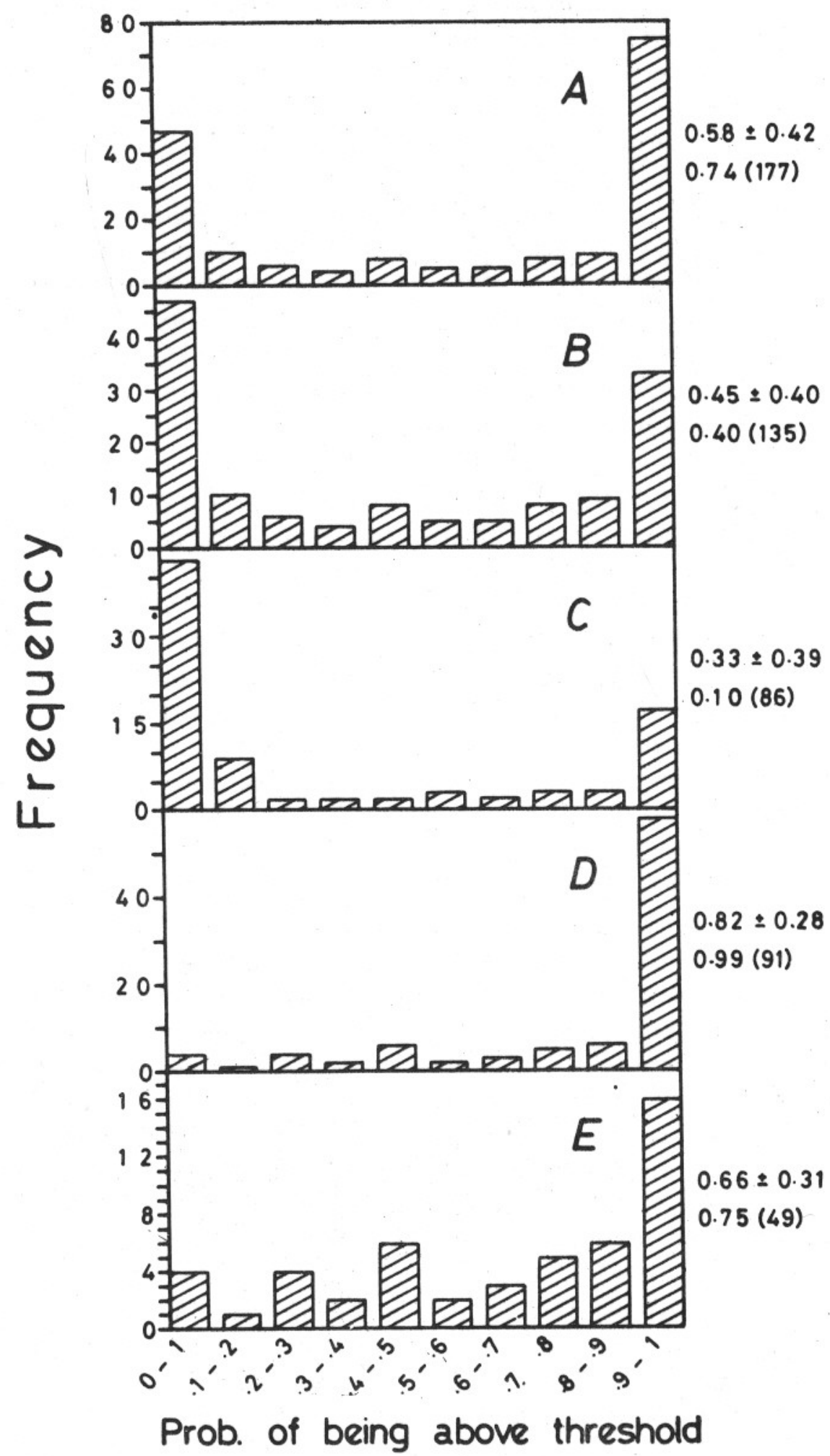

Figure 7. Probability of the relatedness estimates being higher than 0.5 . Using the normal approximation the area under the curve which is above 0.5 has been computed for each estimate using its mean and standard error shown in figure 1 and appendix 1 . This area is interpreted as the probability that a randomly picked value from the distribution will be higher than 0.5. The distribution of such probability values is shown here, (A) All 177 estimates. (B) All estimates excluding those for $M$. comes. (C) All estimates for highly eusocial species. (D) All estimates for primitively eusocial species. (E) All estimates for primitively eusocial species excluding those for $M$. comes. 
otherwise of workers to skew investment between brood of the two sexes. Since the haplodiploidy threshold computed here depends on the as yet poorly tested assumption that workers invest in brood of the two sexes in the ratio of their relatedness to them, the possibility remains that the threshold relatedness to sisters required for the evolution of eusociality is a mere 0.5 . But using 0.5 as the threshold does not alter these conclusions drastically.

Even before this test was performed, the inability of haplodiploidy by itself to promote social evolution has been suggested for a variety of reasons by a number of investigators (Lin and Michener 1972; Alexander 1974; West-Eberhard 1978; Crozier 1982; Andersson 1984; Stubblefield and Charnov 1986; Venkataraman et al. 1988; Gadagkar 1990a, 1991; Gadagkar et al. 1990). However, the analysis presented here should not be thought of as demolishing a straw man. It is possible in principle for haplodiploidy by itself to promote the origin and maintenance of eusociality. Indeed, in species of the fire ant genus Solenopsis and in such species as Lasioglossum zephyrum, Microstigmus comes, and Mischocyttarus immarginatus, sufficiently high levels of genetic relatedness between sisters are obtained, for haplodiploidy by itself to make worker behaviour more advantageous than direct reproduction (without the need for any limitations on the reproductive output of workers). It is therefore essential that the haplodiploidy hypothesis be put to tests of the kind proposed here. Besides, the differences between different species that will be discovered from such an exercise may be illuminating.

If, as argued here, haplodiploidy by itself cannot select for worker behaviour, the evolution of eusociality remains an essentially unsolved problem in evolutionary biology. One course of action then is to explore factors that might potentially act in conjunction with haplodiploidy and predispose the Hymenoptera to the evolution of eusociality (Seger 1983; Godfrey and Grafen 1988; Frank and Crespi 1989). One such factor is kin recognition. If workers can discriminate between full- and halfsisters among the brood and give preferential aid to the former, this will restore the genetic asymmetry created by haplodiploidy and thus select for worker behaviour (Gadagkar, 1985b). The available evidence indicates, however, that primitively eusocial species are incapable of such kin recognition (Gadagkar 1985b, 1991; Gamboa et al. 1986; Venkataraman et al. 1988). On the other hand, at least some species of highly eusocial insects such as honey bees and some ants appear to have the potential for discriminating full-sisters from half-sisters within their colony (reviewed in Gadagkar 1985b, but see for more recent controversy over this issue, Page et al. 1989, 1990; Carlin and Frumhoff 1990; Oldroyd and Rinderer 1990; Page and Robinson 1990). A second course would be to explore factors unconnected with haplodiploidy that might potentially select for worker behaviour. This has been pursued concurrently with investigations of the role of haplodiploidy, albeit at a rather slow pace (Lin and Michener 1972; Alexander 1974; WestEberhard 1975, 1978; Andersson 1984; Gadagkar 1990a, c, d).

\section{Acknowledgements}

I thank N. V. Joshi, Madhav Gadgil, V. Nanjundiah, David Haig, W. D. Hamilton, Ross Crozier and three anonymous referees for critical reading of an earlier version of this paper. Supported in part by a grant from the Department of Science and Technology, Government of India. 


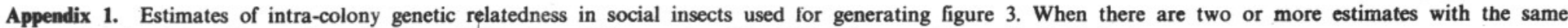
information in all the columns, they come from different populations or localities. Letters in parentheses refer to footnotes.

\begin{tabular}{|c|c|c|c|c|c|c|c|c|c|c|c|}
\hline \multirow{2}{*}{$\begin{array}{l}\text { Sl. } \\
\text { No } \\
\text { (j) }\end{array}$} & \multirow[b]{2}{*}{$\begin{array}{l}\text { Group } \\
\text { (2) }\end{array}$} & \multirow[b]{2}{*}{$\begin{array}{l}\text { Species } \\
\text { (3) }\end{array}$} & \multirow[b]{2}{*}{$\begin{array}{l}\text { Ref } \\
(4)\end{array}$} & \multirow{2}{*}{$\begin{array}{c}\text { Sample } \\
\text { size (a) } \\
(5)\end{array}$} & \multirow[b]{2}{*}{$\begin{array}{c}\text { Mean } \\
(6)\end{array}$} & \multirow{2}{*}{$\begin{array}{l}\text { Std. } \\
\text { error } \\
(7)\end{array}$} & \multicolumn{2}{|c|}{$\begin{array}{l}95 \% \text { confidence } \\
\text { limits (b) }\end{array}$} & \multirow[b]{2}{*}{$\begin{array}{l}\text { Loci } \\
(10)\end{array}$} & \multirow[b]{2}{*}{$\begin{array}{l}\text { Relatedness } \\
\text { (11) }\end{array}$} & \multirow{2}{*}{$\begin{array}{l}\text { In- } \\
\text { breeding } \\
\text { (12) }\end{array}$} \\
\hline & & & & & & & $\begin{array}{l}\text { Lower } \\
\text { (8) }\end{array}$ & $\begin{array}{l}\text { Upper } \\
\text { (9) }\end{array}$ & & & \\
\hline 1 & Ants & Aphaenogaster rudis & 1 & 47 & 0.7500 & (c) & - & - & $M d h-a$ & Workers to female brood (d) & $?(\mathrm{ab})$ \\
\hline 2 & Ants & Formica aquilonia & 2 & 80 & $0-0900$ & $0-0900$ & -0.0864 & 0.2664 & $P g i$ & Among workers & NS $(z)$ \\
\hline 3 & Ants & Formica exsecta & 3 & 41 & $0-0400$ & $0-0700$ & -0.0972 & 0.1772 & Idh & Among workers & NS $(z)$ \\
\hline 4 & Ants & Formica exsecta & 3 & 41 & 0.1000 & $0-0700$ & -0.0372 & 0.2372 & $M d h-a$ & Among workers & NS(z) \\
\hline 5 & Ants & Formica exsecta & 3 & 30 & 0.0900 & 0.0800 & -0.0668 & 0.2468 & $M d h-a$ & Among workers & NS $(z)$ \\
\hline 6 & Ants & Formica exsecta & 3 & 20 & 0.6200 & 0.1300 & 0.3652 & 0.8748 & $M d h-a$ & Among workers & 0.19 (aa) \\
\hline 7 & Ants & Formica exsecta & 3 & 14 & 0.7800 & $0-1300$ & 0.5252 & 1.0348 & $M d h-a$ & Among workers & 0.42 (aa) \\
\hline 8 & Ants & Formica polyctena & 2 & 18 & 0.2900 & 0.1500 & -0.0040 & 0.5840 & Pgi & Among workers & NS $(z)$ \\
\hline 9 & Ants & Formica polyctena & 2 & 10 & 0.3000 & 0.2300 & -0.1508 & 0.7508 & $P g i$ & Among workers & NS(z) \\
\hline 10 & Ants & Formica pressilabris & 3 & 18 & 0.2900 & 0.1300 & 0.0352 & 0.5448 & $M d h-a$ & Among workers & NS (z) \\
\hline 11 & Ants & Formica pressilabris & 3 & 21 & 0.0700 & 0.0800 & -0.0868 & 0.2268 & $M d h-a$ & Among'workers & NS (z) \\
\hline 12 & Ants & Formica sanguinea & 4 & 10 & 0.3780 & $0 \cdot 1730$ & $0-0389$ & 0.7171 & $M d h-2$ & Female brood to workers & NS $(z)$ \\
\hline 13 & Ants & Formica sanguinea & 5 & 17 & 0.1900 & (c) & - & - & $M d h-2$ & Among workers & NS $(z)$ \\
\hline 14 & Ants & Formica sanguinea & 5 & 26 & 0.3800 & (c) & - & - & $M d h-2$ & Female brood to workers & $?(\mathrm{ab})$ \\
\hline 15 & Ants & Formica transkaucasica & 2 & 55 & 0.3300 & 0.0700 & 0.1928 & 0.4672 & $M d h$ & Among workers & NS $(z)$ \\
\hline 16 & Ants & Myrmecia pilosula & 6 & 14 & 0.1720 & 0.0530 & 0.0681 & 0.2759 & $L A P$ & Among workers & $?(\mathrm{ab})$ \\
\hline 17 & Ants & Myrmica rubra & 7 & 7 & $0 \cdot 1056$ & $0 \cdot 1540$ & -0.1962 & $0-4074$ & Est & Among workers & NO(y) \\
\hline 18 & Ants & Myrmica rubra & 7 & 4 & $0-0218$ & 0.1520 & -0.2761 & 0.3197 & Est & Among workers & $\mathrm{NO}(\mathrm{y})$ \\
\hline 19 & Ants & Myrmica rubra & 7 & 9 & 0.5428 & 0.1920 & $0 \cdot 1665$ & 0.9191 & Est & Among workers & $\mathrm{NO}(\mathrm{y})$ \\
\hline 20 & Ants & Myrmica rubra & 7 & 6 & 0.0828 & 0.2500 & -0.4072 & 0.5728 & Est & Among workers & $\mathrm{NO}(\mathrm{y})$ \\
\hline 21 & Ants & Nothomyrmecia macrops & 8 & 4 & $0-1620$ & 0.3330 & -0.4907 & 0.8147 & $A M Y$ & Among workers & NS $(z)$ \\
\hline 22 & Ants & Nothomyrmecia macrops & 8 & 4 & $0-3400$ & 0.1900 & -0.0324 & 0.7124 & $A M Y$ & Among workers & NS $(z)$ \\
\hline 23 & Ants & Rhytidoponera confusa & 9 & 19 & $0-8020$ & $0 \cdot 1080$ & 0.5903 & 1.0137 & Est-3 & Among workers & NS $(z)$ \\
\hline 24 & Ants & Rhytidoponera confusa & 9 & 20 & $0-5440$ & 0.1370 & $0 \cdot 2755$ & 0.8125 & Est-3 & Among workers & NS $(z)$ \\
\hline 25 & Ants & Rhytidoponera confusa & 9 & 20 & 0.4800 & $0 \cdot 1400$ & 0.2056 & 0.7544 & Est-3 & Among workers & NS $(z)$ \\
\hline 26 & Ants & Rhytidoponera confusa & 9 & 20 & 0.6910 & 0.1240 & 0.4480 & 0.9340 & $A M Y$ & Among workers & NS (z) \\
\hline 27 & Ants & Rhytidoponera confusa & 9 & 20 & 0.6410 & 0.1300 & 0.3862 & 0.8958 & $A O-2$ & Among workers & NS $(z)$ \\
\hline 28 & Ants & Rhytidoponera confusa & 9 & 8 & 0.7690 & 0.1790 & 0.4182 & $1 \cdot 1198$ & Est-3 & Among workers & $\operatorname{NS}(z)$ \\
\hline 29 & Ants & Rhytidoponera confusa & 9 & 8 & 0.5740 & 0.2340 & $0 \cdot 1154$ & 1.0326 & Est-3 & Among workers & NS(z) \\
\hline 30 & Ants & Rhytidoponera confusa & 9 & 8 & 0.7540 & $0 \cdot 1980$ & 0.3659 & $1 \cdot 1421$ & $A M Y$ & Among workers & NS(z) \\
\hline 31 & Ants & Rhýtidoponera confusa & 9 & 10 & 0.1700 & $0 \cdot 1960$ & -0.2142 & 0.5542 & Est-3 & Among workers & NS $(z)$ \\
\hline
\end{tabular}


Appendix 1. (Continued).

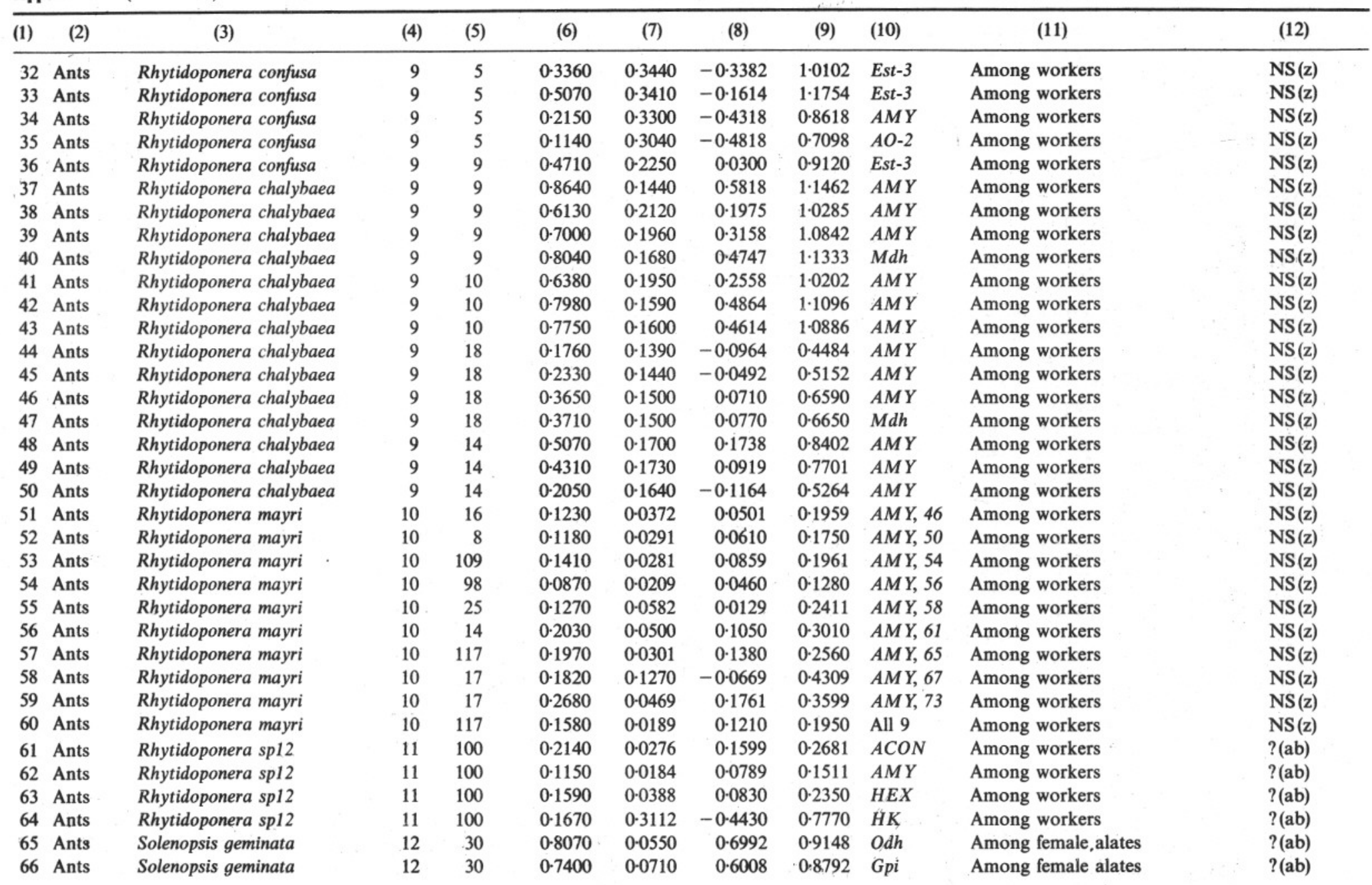


Appendix 1. (Continued).

\begin{tabular}{|c|c|c|c|c|c|c|c|c|c|c|c|}
\hline (1) & (2) & (3) & (4) & (5) & (6) & (7) & (8) & (9) & (10) & (11) & $(12)$ \\
\hline 67 & Ants & Solenopsis geminata & 12 & 30 & 0.7860 & $0 \cdot 1330$ & 0.5253 & $1 \cdot 0467$ & $M p i$ & Among female alates & $?(\mathrm{ab})$ \\
\hline 68 & Ants & Solenopsis geminata & 12 & 30 & $0 \cdot 8120$ & 0.0560 & 0.7022 & 0.9218 & $L d h-1$ & Among female alates & $?(\mathrm{ab})$ \\
\hline 69 & Ants & Solenopsis geminata & 12 & 30 & 0.7880 & 0.0300 & $0 \cdot 7292$ & 0.8468 & All Loci & Among female alates & $?(\mathrm{ab})$ \\
\hline 70 & Ants & Solenopsis invicta & 13 & 55 & 0.7470 & 0.0500 & 0.6490 & 0.8450 & Agp-1 & Among female alates & NS $(z)$ \\
\hline 71 & Ants & Solenopsis invicta & 13 & 55 & 0.6800 & 0.0570 & 0.5683 & 0.7917 & Est-4 & Among female alates & NS (z) \\
\hline 72 & Ants & Solenopsis invicta & 13 & 26 & 0.0840 & $0 \cdot 0600$ & -0.0336 & $0 \cdot 2016$ & Agp-1 & Among female alates & NS (z) \\
\hline 73 & Ants & Solenopsis invicta & 13 & 26 & 0.0350 & 0.0450 & -0.0532 & $0 \cdot 1232$ & Est -4 & Among female alates & NS $(z)$ \\
\hline 74 & Ants & Solenopsis richteri & 12 & 58 & 0.7380 & 0.0430 & 0.6537 & 0.8223 & Est-2 & Among female alates & $?(\mathrm{ab})$ \\
\hline 75 & $\mathrm{HB}(\mathrm{r})$ & Apis mellifera & 14 & 5 & $0.2500(\mathrm{e})$ & (c) & - & - & $M d h$ & Among workers & $?(\mathrm{ab})$ \\
\hline 76 & VW (s) & Paravespula maculifrons & 15 & 20 & $0 \cdot 3200$ & 0.0600 & $0 \cdot 2024$ & 0.4376 & $4(f)$ & Among female progeny & $?(\mathrm{ab})$ \\
\hline 77 & VW(s) & Vespula squamosa & 15 & 17 & 0.4030 & 0.0730 & 0.2599 & 0.5461 & $3(g)$ & Among female progeny & $?(\mathrm{ab})$ \\
\hline 78 & $\mathrm{SFW}(\mathrm{t})$ & Parachartergus colobopterus & 16 & 15 & $0 \cdot 1010$ & $0 \cdot 0660$ & -0.0284 & 0.2304 & Pep & Among female nestmates & NS (z) \\
\hline 79 & $\mathrm{SFW}(\mathrm{t})$ & Parachartergus colobopterus & 16 & 15 & $0 \cdot 1520$ & $0 \cdot 0330$ & $0 \cdot 0873$ & $0 \cdot 2167$ & $H K$ & Among female nestmates & NS $(z)$ \\
\hline 80 & SFW $(t)$ & Parachartergus colobopterus & 16 & 15 & $0 \cdot 1130$ & $0 \cdot 0510$ & $0 \cdot 0130$ & $0 \cdot 2130$ & Both & Among female nestmates & $\operatorname{NS}(z)$ \\
\hline 81 & SFW $(t)$ & Polybia occidentalis & 16 & 21 & $0 \cdot 3030$ & 0.0900 & $0 \cdot 1266$ & 0.4794 & Est & Among female nestmates & NS $(z)$ \\
\hline 82 & SFW $(t)$ & Polybia occidentalis & 16 & 21 & $0 \cdot 3020$ & 0.0620 & $0 \cdot 1805$ & 0.4235 & $M p i$ & Among female nestmates & NS $(z)$ \\
\hline 83 & $\mathrm{SFW}(\mathrm{t})$ & Polybia occidentalis & 16 & 21 & 0.6450 & $0 \cdot 2760$ & $0 \cdot 1040$ & $1 \cdot 1860$ & $I d h$ & Among female nestmates & NS (z) \\
\hline 84 & SFW (t) & Polybia occidentalis & 16 & 21 & $0 \cdot 3010$ & 0.3080 & -0.3027 & 0.9047 & $H K$ & Among female nestmates & NS (z) \\
\hline 85 & $\mathrm{SFW}(\mathrm{t})$ & Polybia occidentalis & 16 & 21 & 0.3390 & $0-0470$ & $0 \cdot 2469$ & 0.4311 & All 4 & Among female nestmates & NS (z) \\
\hline 86 & SFW (t) & Polybia sericea & 16 & 18 & 0.2760 & 0.0810 & $0 \cdot 1172$ & 0.4348 & $M p i$ & Among female nestmates & NS (z) \\
\hline 87 & SFW $(t)$ & Polybia sericea & 16 & 18 & 0.3570 & $0 \cdot 1320$ & 0.0983 & 0.6157 & $M d h$ & Among female nestmates & $\operatorname{NS}(z)$ \\
\hline 88 & $\mathrm{SFW}(\mathrm{t})$ & Polybia sericea & 16 & 18 & 0.1230 & 0.1400 & $-0 \cdot 1514$ & 0.3974 & Pgm & Among female nestmates & $\operatorname{NS}(z)$ \\
\hline 89 & $\mathrm{SFW}(\mathrm{t})$ & Polybia sericea & 16 & 18 & 0.1390 & $0 \cdot 1460$ & $-0 \cdot 1472$ & 0.4252 & $A k$ & Among female nestmates & NS $(z)$ \\
\hline 90 & $\mathrm{SFW}(\mathrm{t})$ & Polybia sericea & 16 & 18 & $0 \cdot 2760$ & 0.0690 & $0 \cdot 1408$ & 0.4112 & All 4 & Among female nestmates & NS(z) \\
\hline 91 & $\operatorname{PEB}(u)$ & Exoneura bicolor & 17 & 98 & 0.4850 & 0.0600 & 0.3674 & 0.6026 & Est & Among nestmates $(\mathrm{h}, \mathrm{i})$ & NS(z) \\
\hline 92 & $\operatorname{PEB}(u)$ & Exoneura bicolor & 17 & 98 & 0.4810 & 0.0510 & $0 \cdot 3810$ & 0.5803 & Est & Among nestmates $(\mathrm{h}, \mathrm{j})$ & NS (z) \\
\hline 93 & $\operatorname{PEB}(\mathrm{u})$ & Exoneura bicolor & 17 & 88 & 0.5970 & 0.0620 & 0.4755 & 0.7185 & Est & Among cofoundresses $(k, i)$ & NS(z) \\
\hline 94 & $\operatorname{PEB}(\mathrm{u})$ & Exoneura bicolor & 17 & 88 & 0.5760 & 0.0560 & 0.4662 & 0.6858 & Est & Among cofoundresses $(\mathrm{k}, \mathrm{j})$ & NS (z) \\
\hline 95 & PEB (u) & Exoneura bicolor & 17 & 34 & 0.4910 & 0.0770 & $0 \cdot 3401$ & 0.6419 & Est & Among female brood $(1, \mathrm{i})$ & NS $(z)$ \\
\hline 96 & PEB(u) & Exoneura bicolor & 17 & 34 & $0 \cdot 4990$ & $0-0780$ & $0 \cdot 3461$ & 0.6519 & Est & Among female brood $(1, j)$ & $\operatorname{NS}(z)$ \\
\hline 97 & PEB (u) & Exoneura bicolor & 17 & 27 & 0.5890 & 0.0880 & $0 \cdot 4165$ & 0.7615 & Est & Among female brood $(h, i)$ & NS (z) \\
\hline 98 & $\operatorname{PEB}(\mathrm{u})$ & Exoneura bicolor & 17 & 27 & 0.5940 & $0 \cdot 0810$ & 0.4352 & 0.7528 & Est & Among female brood $(h, j)$ & $\mathrm{NS}(\mathrm{z})$ \\
\hline 99 & $\operatorname{PEB}(u)$ & Lasioglossum zephyrum & 18 & 20 & 0.8099 & $0 \cdot 2003$ & 0.4173 & $1 \cdot 2025$ & Gda & Among female nestmates(i) & NS (z) \\
\hline 100 & $\operatorname{PEB}(\mathrm{u})$ & Lasioglossum zephyrum & 18 & 20 & 0.8390 & $0 \cdot 1011$ & $0 \cdot 6408$ & 1.0372 & $P e p-V L-1$ & Among female nestmates (i) & NS $(z)$ \\
\hline 101 & $\operatorname{PEB}(\mathrm{u})$ & Lasioglossum zephyrum & 18 & 20 & 0.8245 & $0-0145$ & 0.7961 & 0.8529 & Total & Among female nestmates (i) & NS (z) \\
\hline
\end{tabular}


Appendix 1. (Continued).

\begin{tabular}{|c|c|c|c|c|c|c|c|c|c|c|c|}
\hline (1) & (2) & (3) & (4) & (5) & (6) & (7) & (8) & (9) & (10) & (11) & (12) \\
\hline 102 & PEB (u) & Lasioglossum zephyrum & 18 & 10 & 0.8960 & 0.4471 & $0-0197$ & $1 \cdot 7723$ & Pep-VL & Among female nestmates (i) & NS $(z)$ \\
\hline 103 & $\operatorname{PEB}(u)$ & Lasioglossum zephyrum & 18 & 11 & 0.5663 & 0.3145 & -0.0501 & $1 \cdot 1827$ & $G d a$ & Among female nestmates (i) & NS $(z)$ \\
\hline 104 & $\operatorname{PEB}(\mathrm{u})$ & Lasioglossum zephyrum & 18 & 11 & $0 \cdot 3628$ & 0.2102 & -0.0492 & 0.7748 & Pep-VL & Among female nestmates (i) & NS $(z)$ \\
\hline 105 & PEB (u) & Lasioglossum zephyrum & 18 & 11 & 0.4646 & $0 \cdot 1018$ & 0.2651 & 0.6641 & Total & Among female nestmates (i) & NS $(z)$ \\
\hline 106 & $\operatorname{PEB}(\mathrm{u})$ & Lasioglossum zephyrum & 18 & 20 & 0.7837 & 0.2259 & 0.3409 & $1 \cdot 2265$ & Gda & Among female nestmates (j) & NS(z) \\
\hline 107 & $\mathrm{PEB}(\mathrm{u})$ & Lasioglossum zephyrum & 18 & 20 & 0.8134 & $0-1021$ & 0.6133 & $1 \cdot 0135$ & $P e p-V L-1$ & Among female nestmates (j) & NS $(z)$ \\
\hline 108 & PEB (u) & Lasioglossum zephyrum & 18 & 20 & 0.7986 & $0-0149$ & 0.7694 & 0.8278 & Total & Among female nestmates (j) & NS $(z)$ \\
\hline 109 & PEB (u) & Lasioglossum zephyrum & 18 & 10 & 0.8276 & $0 \cdot 4145$ & 0.0152 & 1.6400 & Pep-VL & Among female nestmates (j) & NS(z) \\
\hline 110 & PEB (u) & Lasioglossum zephyrum & 18 & 11 & 0.5833 & 0.2305 & $0 \cdot 1315$ & $1 \cdot 0351$ & $G d a$ & Among female nestmates (j) & NS $(z)$ \\
\hline 111 & PEB (u) & Lasioglossum zephyrum & 18 & 11 & 0.3968 & $0 \cdot 1927$ & $0 \cdot 0191$ & 0.7745 & Pep-VL & Among female nestmates (j) & NS (z) \\
\hline 112 & PEB(u) & Lasioglossum zephyrum & 18 & 11 & 0.4901 & 0.0933 & 0.3072 & 0.6730 & Total & Among female nestmates (j) & NS $(z)$ \\
\hline 113 & PEB(u) & Lasioglossum zephyrum (ac) & 19 & 15 & 0.5000 & $0 \cdot 1700$ & 0.1668 & 0.8332 & $P e p-G L-2$ & Among potential workers & 0.1040 (aa) \\
\hline 114 & PEB (u) & Lasioglossum zephyrum (ac) & 19 & 15 & 0.6700 & $0 \cdot 1600$ & 0.3564 & 0.9836 & Hbdh & Among potential workers & $0 \cdot 1040$ (aa) \\
\hline 115 & $\operatorname{PEB}(u)$ & Lasioglossum zephyrum (ac) & 19 & 15 & 0.5700 & $0 \cdot 1100$ & 0.3544 & 0.7856 & Combined & Among potential workers & 0.1040 (aa) \\
\hline 116 & PEB (u) & Lasioglossum zephyrum (ac) & 19 & 11 & 0.7600 & 0.1000 & 0.5640 & 0.9560 & Pep-GL-2 & Among workers & 0.1040 (aa) \\
\hline 117 & $\operatorname{PEB}(\mathbf{u})$ & Lasioglossum zephyrum (ac) & 19 & 11 & 0.2900 & $0-0800$ & 0.1332 & 0.4468 & $H b d h$ & Among workers & $0 \cdot 1040$ (aa) \\
\hline 118 & $\operatorname{PEB}\left(u^{2}\right.$ & Lasioglossum zephyrum (ac) & 19 & 11 & 0.4300 & $0 \cdot 1000$ & 0.2340 & 0.6260 & Combined & Among workers & $0 \cdot 1040(\mathrm{aa})$ \\
\hline 119 & PEB (u) & Lasioglossum zephyrum (ac) & 19 & 9 & 0.6600 & 0.1800 & 0.3072 & 1.0128 & Pep-GL-2 & Among gynes & $0 \cdot 1040$ (aa) \\
\hline 120 & $\mathrm{PEB},(\mathrm{u})$ & Lasioglossum zephyrum (ac) & 19 & 9 & 0.7400 & 0.1100 & 0.5244 & 0.9556 & Hbdh & Among gynes & $0 \cdot 1040$ (aa) \\
\hline 121 & $\operatorname{PEB}(\mathrm{u})$ & Lasioglossum zephyrum $(a c)$ & 19 & 9 & 0.7200 & 0.0900 & 0.5436 & 0.8964 & Combined & Among gynes & $0 \cdot 1040$ (aa) \\
\hline 122 & $\operatorname{PEB}(\mathrm{u})$ & Lasioglossum zephyrum (ac) & 19 & 12 & 0.5900 & 0.1600 & 0.2764 & 0.9036 & $P e p-G L-2$ & Among female nestmates & 0.1040 (aa) \\
\hline 123 & $\operatorname{PEB}(u)$ & Lasioglossum zephyrum (ac) & 19 & 12 & 0.5000 & $0 \cdot 1000$ & $0 \cdot 3040$ & 0.6960 & $H b d h$ & Among female nestmates & 0.1040 (aa) \\
\hline 124 & $\operatorname{PEB}(u)$ & Lasioglossum zephyrum $(a c)$ & 19 & 12 & 0.5300 & $0 \cdot 1000$ & 0.3340 & 0.7260 & Combined & Among female nestmates & $0 \cdot 1040$ (aa) \\
\hline 125 & PEW (v) & Microstigmus comes & 20 & 97 & 0.6050 & 0.0440 & 0.5188 & 0.6912 & Pep & Among female nestmates $(m, n, a e)$ & $\operatorname{NS}(z)$ \\
\hline 126 & PEW (v) & Microstigmus comes & 20 & 97 & 0.6630 & $0-0440$ & 0.5768 & 0.7492 & Gpi & Among female nestmates $(m, n, a e)$ & NS $(z)$ \\
\hline 127 & PEW (v) & Microstigmus comes & 21 & 97 & 0.6330 & $0-0320$ & 0.5703 & 0.6957 & Pep; Gpi & Among female nestmates $(\mathrm{m}, \mathrm{n}, \mathrm{ae})$ & NS $(z)$ \\
\hline 128 & PEW (v) & Microstigmus comes & 20 & 72 & 0.6520 & 0.0450 & 0.5638 & 0.7402 & Pep & Among female nestmates (m, $n$, af) & NS $(z)$ \\
\hline 129 & PEW (v) & Microstigmus comes & 20 & 72 & $0 \cdot 7120$ & 0.0450 & 0.6238 & 0.8002 & Gpi & Among female nestmates $(m, n, a f)$ & NS $(z)$ \\
\hline 130 & PEW (v) & Microstigmus comes & 21 & 72 & 0.6810 & $0-0330$ & 0.6163 & 0.7457 & Pep; Gpi & Among female nestmates (m, $n$, af) & NS $(z)$ \\
\hline 131 & PEW (v) & Microstigmus comes & 20 & 56 & $0-6140$ & 0.0520 & 0.5121 & 0.7159 & Pep & Among female nestmates (m, n, ag) & NS $(z)$ \\
\hline 132 & PEW (v) & Microstigmus comes & 20 & 56 & 0.7140 & 0.0620 & 0,5925 & 0.8355 & Gpi & Among female nestmates $(\mathrm{m}, \mathrm{n}, \mathrm{ag})$ & $\operatorname{NS}(z)$ \\
\hline 133 & $\mathrm{PEW}(\mathrm{v})$ & Microstigmus comes & 21 & 56 & 0.6640 & $0-0420$ & 0.5817 & 0.7463 & Pep; Gpi & Among female nestmates (m, n, ag) & NS (z) \\
\hline 134 & PEW (v) & Microstigmus comes & 20 & 111 & 0.6250 & 0.0400 & 0.5466 & 0.7034 & Pep & Among female nestmates $(m, 0, a c)$ & NS $(z)$ \\
\hline 135 & PEW (v) & Microstigmus comes & 20 & 111 & $0-6580$ & 0.0420 & 0.5757 & 0.7403 & Gpi & Among female nestmates $(\mathrm{m}, \mathrm{o}, \mathrm{ae})$ & NS $(z)$ \\
\hline
\end{tabular}

102 PEB(u) Lasioglossum zephyrum.

0.5663

$0.3145-0.0501$

$1 \cdot 1827 G d a$

NS (z)

0.2651

0.6641 Total

Among female nestmates (i)

NS (z)

0.7837

0.2259

Among female nestmates (j)

0.7986

0.4145

0.8278 Total

NS $(z)$

NS(z)

NS $(z)$

$0 \cdot 1040$ (aa)

0.1040 (aа)

$0 \cdot 1040$ (aa)

0.1040 (aa)

0.7400

0.1100

0.5244

$0 \cdot 1040$ (aa)

$0 \cdot 1040$ (aa)

0.1040 (aa)

0.5000

0.1000

0.3340

$0 \cdot 1040$ (aa)

0.6050

$0-0440$

0.5768

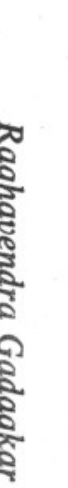

$0-6580$

0.0420

0.5757

Among fernale nestmates (m, o, ae) NS(z) 
Appendix 1. (Continued).

\begin{tabular}{|c|c|c|c|c|c|c|c|c|c|c|c|}
\hline (1) & (2) & (3) & (4) & (5) & (6) & (7) & (8) & (9) & (10) & (11) & (12) \\
\hline 136 & PEW (v) & Microstigmus comes & 21 & 111 & $0 \cdot 6400$ & 0.0300 & 0.5812 & 0.6988 & Pep; Gpi & Among female nestmates (m, o, ae) & NS $(z)$ \\
\hline 137 & PEW (v) & Microstigmus comes & 20 & 88 & $0 \% 6560$ & 0.0390 & 0.5796 & 0.7324 & Pep & Among female nestmates (m, o, af) & NS $(z)$ \\
\hline 138 & PEW(v) & Microstigmus comes & 20 & 88 & 0.7000 & $0-0410$ & 0.6196 & 0.7804 & Gpi & Among female nestmates ( $m, 0$, af ) & NS $(z)$ \\
\hline 139 & PEW (v) & Microstigmus comes & 21 & 88 & 0.6770 & 0.0290 & 0.6202 & 0.7338 & Pep; Gpi & Among female nestmates (m, o, af) & NS $(z)$ \\
\hline 140 & PEW (v) & Microstigmus comes & 20 & 64 & 0.6630 & 0.0430 & 0.5787 & 0.7473 & Pep & Among female nestmates (m, o, ag) & NS $(z)$ \\
\hline 141 & PEW (v) & Microstigmus comes & 20 & 64 & 0.7300 & 0.0530 & 0.6261 & 0.8339 & Gpi & Among female nestmates (m,o,ag) & NS $(z)$ \\
\hline 142 & PEW (v) & Microstigmus comes & 21 & 64 & 0.6950 & 0.0350 & 0.6264 & 0.7636 & Pep; Gpi & Among female nestmates $(\mathrm{m}, \mathrm{o}, \mathrm{ag})$ & NS $(z)$ \\
\hline 143 & PEW (v) & Microstigmus comes & 20 & 97 & 0.6150 & 0.0430 & 0.5307 & 0.6993 & Pep & Among female nestmates ( $p, n, a e)$ & NS $(z)$ \\
\hline 144 & $\operatorname{PEW}(\mathbf{v})$ & Microstigmus comes & 20 & 97 & 0.6820 & 0.0490 & 0.5860 & 0.7780 & $G p i$ & Among female nestmates ( $\mathrm{p}, \mathrm{n}, \mathrm{ae})$ & NS $(z)$ \\
\hline 145 & PEW (v) & Microstigmus comes & 21 & 97 & 0.6470 & 0.0350 & 0.5784 & 0.7156 & Pep; Gpi & Among female nestmates ( $\mathrm{p}, \mathrm{n}, \mathrm{ae})$ & NS (z) \\
\hline 146 & PEW (v) & Microstigmus comes & 20 & 72 & 0.6390 & 0.0450 & 0.5508 & 0.7272 & Pep & Among female nestmates ( $\mathrm{p}, \mathrm{n}$, af $)$ & NS $(z)$ \\
\hline 147 & PEW (v) & Microstigmus comes & 20 & 72 & 0.7070 & 0.0520 & 0.6051 & 0.8089 & Gpi & Among female nestmates ( $\mathrm{p}, \mathrm{n}$, af) & NS $(z)$ \\
\hline 148 & PEW (v) & Microstigmus comes & 21 & 72 & 0.6720 & 0.0370 & 0.5995 & 0.7445 & Pep; Gpi & Among female nestmates ( $\mathrm{p}, \mathrm{n}$, af) & NS $(z)$ \\
\hline 149 & PEW(v) & Microstigmus comes & 20 & 56 & 0.6160 & 0.0510 & 0.5160 & 0.7160 & Pep & Among female nestmates ( $\mathrm{p}, \mathrm{n}, \mathrm{ag})$ & NS $(z)$ \\
\hline 150 & PEW (v) & Microstigmus comes & 20 & 56 & 0.7070 & 0.0640 & $0 \cdot 5816$ & 0.8324 & $G p i$ & Among female nestmates ( $p, n, a g)$ & NS $(z)$ \\
\hline 151 & PEW (v) & Microstigmus comes & 21 & 56 & 0.6620 & 0.0440 & 0.5758 & 0.7482 & Pep; Gpi & Among female nestmates ( $\mathrm{p}, \mathrm{n}, \mathrm{ag})$ & NS $(z)$ \\
\hline 152 & PEW (v) & Microstigmus comes & 20 & 111 & 0.6460 & 0.0370 & 0.5735 & 0.7185 & Pep & Among female nestmates (p,o,ae) & NS $(z)$ \\
\hline 153 & $\operatorname{PEW}(v)$ & Microstigmus comes & 20 & 111 & 0.6870 & 0.0470 & 0.5949 & 0.7791 & Gpi & Among female nestmates $(\mathrm{p}, \mathrm{o}, \mathrm{ae})$ & NS $(z)$ \\
\hline 154 & PEW (y) & Microstigmus comes & 21 & 111 & 0.6650 & $0-0310$ & $0 \cdot 6042$ & 0.7258 & Pep; Gpi & Among female nestmates (p,o,ae) & NS $(z)$ \\
\hline 155 & PEW (v) & Microstigmus comes & 20 & 88 & 0.6610 & $0-0390$ & $0 \cdot 5846$ & 0.7374 & Pep & Among female nestmates ( $p, o$, af $)$ & NS $(z)$ \\
\hline 156 & PEW (v) & Microstigmus comes & 20 & 88 & 0.7070 & 0.0480 & 0.6129 & 0.8011 & Gpi & Among female nestmates ( $\mathrm{p}, \mathrm{o}, \mathrm{af})$ & NS $(z)$ \\
\hline 157 & PEW (v) & Microstigmus comes & 21 & 88 & 0.6820 & $0-0330$ & 0.6173 & 0.7467 & Pep; Gpi & Among female nestmates (p,o, af) & NS $(z)$ \\
\hline 158 & PEW(v) & Microstigmus comes & 20 & 64 & 0.6660 & 0.0430 & 0.5817 & 0.7503 & Pep & Among female nestmates (p,o,ag) & NS $(z)$ \\
\hline 159 & PEW (v) & Microstigmus comes & 20 & 64 & 0.7240 & 0.0570 & $0 \cdot 6123$ & 0.8357 & $G p i$ & Among female nestmates ( $\mathrm{p}, \mathrm{o}, \mathrm{ag})$ & NS $(z)$ \\
\hline 160 & PEW (v) & Microstigmus comes & 21 & 64 & 0.6930 & 0.0370 & $0 \cdot 6205$ & 0.7655 & Pep; Gpi & Among female nestmates $(\mathrm{p}, \mathrm{o}, \mathrm{ag})$ & NS $(z)$ \\
\hline 161 & PEW (v) & Microstigmus comes & 21 & 97 & 0.5960 & $0-0380$ & 0.5215 & 0.6705 & Pep; Gpi & Among female nestmates (q, $n$, ae) & NS $(z)$ \\
\hline 162 & PEW (v) & Microstigmus comes & 21 & 72 & 0.6230 & $0-0380$ & 0.5485 & 0.6975 & Pep; Gpi & Among female nestmates $(q, n$, af $)$ & NS $(z)$ \\
\hline 163 & PEW (v) & Microstigmus comes & 21 & 56 & 0.6080 & 0.0510 & 0.5080 & 0.7080 & Pep; Gpi & Among female nestmates (q, n,ag) & NS $(z)$ \\
\hline 164 & PEW (v) & Microstigmus comes & 21 & 111 & 0.6180 & 0.0230 & 0.5729 & 0.6631 & Pep; Gpi & Among female nestmates $(\mathrm{q}, \mathrm{o}, \mathrm{ae})$ & NS $(z)$ \\
\hline 165 & PEW (v) & Microstigmus comes & 21 & 88 & 0.6370 & 0.0260 & 0.5860 & 0.6880 & Pep; Gpi & Among female nestmates $(q, 0$, af $)$ & NS $(z)$ \\
\hline 166 & PEW (v) & Microstigmus comes & 21 & 64 & 0.6470 & $0-0320$ & 0.5843 & 0.7097 & Pep; Gpi & Among female nestmates (q, o, ag) & NS $(z)$ \\
\hline 167 & PEW (v) & Mischocyttarus basimacula & 22 & 16 & 0.4350 & 0.1160 & 0.2076 & 0.6624 & 2 loci & Among female nestmates & $?(\mathrm{ab})$ \\
\hline 168 & PEW (v) & Mischocyttarus immarginatus & 22 & 19 & 0.7650 & 0.0360 & 0.6944 & 0.8356 & 3 loci & Among female nestmates & $?(\mathrm{ab})$ \\
\hline 169 & PEW (v) & Polistes annularis & 22 & 34 & 0.3060 & $0-0750$ & 0.1590 & 0.4530 & 2 loci & Among female nestmates & $?(\mathrm{ab})$ \\
\hline
\end{tabular}




\begin{tabular}{|c|c|c|c|c|c|c|c|c|c|c|c|}
\hline (1) & (2) & (3) & (4) & $(5)$ & (6) & (7) & (8) & (9) & (10) & (11) & (12) \\
\hline 170 & PEW (v) & Polistes apachus-bellicosus & 23 & 2 & $0.4690(x)$ & (c) & - & - & 1-4 loci & Workers to female pupae & $?(\mathrm{ab})$ \\
\hline 171 & PEW (v) & Polistes bellicosus & 22 & 31 & $0 \cdot 3380$ & $0 \cdot 1480$ & 0.0479 & 0.6281 & 1 locus & Among female nestmates & $?(\mathrm{ab})$ \\
\hline 172 & PEW (v) & Polistes canadensis & 22 & 20 & $0 \cdot 3390$ & 0.0970 & $0 \cdot 1489$ & 0.5291 & 3 loci & Among female nestmates & $?(\mathrm{ab})$ \\
\hline 173 & PEW (v) & Polistes carolinus & 22 & 16 & 0.6300 & 0.0590 & 0.5144 & 0.7456 & 6 loci & Among female nestmates & $?(\mathrm{ab})$ \\
\hline 174 & PEW (v) & Polistes dominulus & 22 & 8 & 0.6520 & 0.0880 & 0.4795 & 0.8245 & 4 loci & Among female nestmates & $?(\mathrm{ab})$ \\
\hline 175 & PEW(v) & Polistes dorsalis & 22 & 21 & 0.6070 & $0-0790$ & 0.4522 & 0.7618 & 4 loci & Among female nestmates & ?(ab) \\
\hline 176 & PEW(v) & Polistes exclamans & 22 & 46 & 0.5570 & 0.0850 & 0.3904 & 0.7236 & 1 locus & Among female nestmates & $?(\mathrm{ab})$ \\
\hline 177 & PEW(v) & Polistes exclamans & 22 & 33 & 0.6920 & $0 \cdot 1040$ & 0.4882 & 0.8958 & 3 loci & Among female nestmates & ?(ab) \\
\hline 178 & PEW (v) & Polistes exclamans & 23 & 11 & $0 \cdot 3876(x)$ & (c) & - & - & 1-3 loci & Workers to female pupae & $?(\mathrm{ab})$ \\
\hline 179 & PEW(v) & Polistes gallicus & 22 & 12 & 0.8030 & $0 \cdot 1500$ & 0.5090 & 1.0970 & 2 loci & Among female nestmates & $?(\mathrm{ab})$ \\
\hline 180 & PEW(v) & Polistes instabilis & 22 & 42 & 0.5250 & $0-0640$ & 0.3996 & 0.6504 & 2 loci & Among female nestmates & $?(\mathrm{ab})$ \\
\hline 181 & PEW(v) & Polistes metricus & 22 & 19 & 0.5670 & 0.0870 & 0.3965 & 0.7375 & 5 loci & Among female nestmates & ?(ab) \\
\hline 182 & PEW (v) & Polistes metricus & 24 & ? & $0.6300(w)$ & (c) & - & - & 5 Est loci & Workers to female pupae & No(y) \\
\hline 183 & PEW(v) & Polistes nimpha & 22 & 10 & 0.5400 & 0.1620 & 0.2225 & 0.8575 & 3 loci & Among female nestmates & ?(ab) \\
\hline 184 & PEW(v) & Polistes versicolor & 22 & 18 & 0.3710 & 0.0840 & 0.2064 & 0.5356 & 4 loci & Among female nestmates & $?(\mathrm{ab})$ \\
\hline 185 & PEW (v) & Ropalidia marginata & 25 & 4 & $0.5300(\mathrm{ad})$ & (c) & - & - & 2 Est loci & Among female offspring & ?(ab) \\
\hline
\end{tabular}

Footnotes: (a) No. of nests studied; (b) Computed as mean \pm (S.E. $\times 1.96)$ if not already given; (c) S.E. not given; (d) Inferred because colonies consist of a single oncemated queen and her progeny; (e) Inferred because queens simultaneously use sperms from at least five to six males; (f) The 4 loci used are Pgm-1,3; Hbdh; Mpi; Agp1,2; (g) The 3 loci used are Pgm-1; Est-1,2; Hbdh; (h) Over wintered nests; (i) Equal weighted estimate; (j) Size weighted estimate; (k) Cofoundress nests; (l) Newly founded nests; (m) Unweighted global estimate; (n) Adult females; (o) Adult and emerged females; (p) Weighted global estimate; (q) Weighted local estimate; (r) $\mathrm{HB}=$ honey bee; (s) VW= vespine wasps; (t) SFW=swarm-founding wasps; (u) PEB=primitively eusocial bees; (v) PEW=primitively eusocial wasps; (w) Value computed by Lester and Selander (1981); (x) The original values given in this paper are for relatedness between workers and brood (including male and female brood). Normally such values can directly be compared with 0.5 , the relatedness between a solitary foundress and her brood. However, it is not clear if all the pupae in these nests were destined to become reproductives. I have therefore omitted those nests which had male pupae and used values from nests which had only female pupae; (y) Absence of inbreeding inferred; (z) Not significantly different from zero; (aa) Significantly greater than zero; (ab) No information is available regarding inbreeding; (ac) The equivalent name Dialictus zephyrus is used in the original paper; (ad) This value is computed from the data given in the paper; (ae) Nest $>3$ wasps; (af) Nest $>4$ wasps; (ag) Nest $>5$ wasps.

References used in Appendix: (1) Crozier (1973); (2) Pamilo (1982); (3) Pamilo and Rosengren (1984); (4) Pamilo and Varvio-Aho (1979); (5) Pamilo (1981); (6) Craig and Crozier (1979); (7) Pearson (1983); (8) Ward and Taylor (1981); (9) Ward (1983); (10) Crozier et al. (1984); (11) Crozier and Pamilo (1986); (12) Ross et al. (1988); (13) Ross and Fletcher (1985); (14) Page and Metcalf (1982); (15) Ross (1986); (16) Queller et al. (1988); (17) Schwarz (1987); (18) Crozier et al. (1987); (19) Kukuk (1989); (20) Ross and Matthews (1989b); (21) Ross and Matthews (1989a); (22) Strassmann et al. (1989); (23) Lester and Selander (1981); (24) Metcalf and Whitt (1977a,b); (25) Muralidharan et al. (1986). 


\section{References}

Alexander R. D. 1974 The evolution of social behavior. Annu. Rev. Ecol. Syst. 5: 325-383

Alexander R. D. and Sherman P. W. 1977 Local mate competition and parental investment in social insects. Science 196: 494-500.

Anderson R. H. 1963 The laying worker in the Cape honey bee, Apis mellifera capensis. J. Apic. Res. 2: 85-92

Andersson M. 1984 The evolution of eusociality. Annu. Rev. Ecol. Syst. 15: 165-189

Aoki S. 1982 Soldiers and altruistic dispersal in Aphids. In The biology of social insects (eds) M. D. Breed, C. D. Michener and H. E. Evans (Boulder, Colorado: Westview Press) pp. 154-158

Boomsma J. J. 1989 Sex-investment ratios in ants: Has female bias been systematically overestimated? Am. Nat. 133: 517-532

Bourke A. F. G. 1988 Worker reproduction in the higher eusocial hymenoptera. Q. Rev. Biol. 63: 291311

Carlin N. F. and Frumhoff P. C. 1990 Nepotism in honey bees. Nature (London) 346: 706-707

Charnov E. L. 1978 Sex-ratio selection in ousocial hymenoptera. Am. Nat. 112: 317-326

Charnov E. L. 1982 The theory of sex allocation (Princeton, New Jersey: Princeton University Press)

Craig R. 1979 Parental manipulation, kin selection and the evolution of altruism. Evolution 33: 319-334

Craig R. 1980 Sex investment ratios in social Hymenoptera. Am. Nat. 116: 311-323

Craig R. and Crozier R. H. 1979 Relatedness in the polygynous ant Myrmecia pilosula. Evolution 33: 335-341

Crozier R. H. 1973 Apparent differential selection at an isozyme locus between queens and workers of the ant Aphaenogaster rudis. Genetics 73: 313-318

Crozier R. H. 1982 On insects and insects: twists and turns in our understanding of the evolution of eusociality. In The biology of social insects (eds) M. D. Breed, C. D. Michener, H. E. Evans (Boulder, Colorado: Westview Press) pp. 4-9

Crozier R. H. and Pamilo P. 1986 Relatedness within and between colonies of a queenless ant species of the genus Rhytidoponera (Hymenoptera: Formicidae): Entomol. Gener. 11: 113-117

Crozier R. H., Pamilo P. and Crozier Y. C. 1984 Relatedness and microgeographic genetic variation in Rhytidoponera mayri, an Australian arid-zone ant. Behav. Ecol. Sociobiol. 15: 143-150

Crozier R. H., Smith B. H. and Crozier Y. C. 1987 Relatedness and population structure of the primitively eusocial bee Lasioglossum zephyrum (Hymenoptera: Halictidae) in Kansas. Evolution 41: 902-910

Darwin C. 1859 The origin of species (New York: Collier, 1962)

Fisher R. A. 1930 The genetical theory of natural selection (Oxford: Clarendon Press, 1958) pp. xiv \& 291

Fletcher D. J. C. and Ross K. G. 1985 Regulation of reproduction in eusocial Hymenoptera. Annu. Rev. Entomol. 30: 319-343

Frank S. A. and Crespi B. J. 1989 Synergism between sib-rearing and sex ratio in Hymenoptera. Behav. Ecol. Sociobiol. 24: 155-162.

Gadagkar R. 1985a Evolution of insect sociality - A review of some attempts to test modern theories. Proc. Indian Acad. Sci. (Anim. Sci.) 94: 309-324

Gadagkar R. 1985b Kin recognition in social insects and other animals - A review of recent findings and a consideration of their relevance for the theory of kin selection. Proc. Indian Acad. Sci. (Anim. Sci.) 94: 587-621

Gadakgar R. 1990a Social biology of Ropalidia: Investigations into the origins of eusociality. In Social insects and the environment, Proceedings of the 11th International Congress of IUSSI (eds) G. K. Veeresh, B. Mallik and C. A. Viraktamath (New Delhi: Oxford and IBH) pp. 9-11

Gadagkar R. 1990b The haplodiploidy threshold and social evolution. Curr. Sci. 59: 374-376

Gadagkar R. 1990c Evolution of eusociality: The advantage of assured fitness returns. Philos. Trans. $\boldsymbol{R}$. Soc. London B329: 17-25

Gadagkar R. 1990d Origin and evolution of eusociality: A perspective from studying primitively eusocial wasps. J. Genet. 69: 113-125

Gadagkar R. 1991 Belonogaster, Mischocyttarus, Parapolybia and independent founding Ropalidia. In Social biology of wasps (eds) K. G. Ross and R. W. Matthews (Ithaca, NY: Cornell University Press) pp. 149-190 (in press)

Gadagkar R., Chandrashekara K., Chandran, S. and Bhagavan, S. 1990 Serial polygyny in Ropalidia marginata: Implications for the evolution of eusociality. In Social insects and the environment, Proceedings of the 11th International Congress of IUSSI (eds) G. K. Veeresh, B. Mallik and C. A. Viraktamath (New Delhi: Oxford and IBH) pp. 227-228 
Gamboa G. J., Reeve H. K. and Pfenning-D. W. 1986 The evolution and ontogeny of nestmate recognition in social wasps. Annu. Rev. Entomol. 31: 431-454

Godfrey H. C. J. and Grafen A. 1988 Unmatedness and the evolution of eusociality. Am. Nat. 131: 303305

Grafen A. 1986 Split sex ratios and the evolutionary origins of eusociality. J. Theor. Biol. 122: 95-121

Hamilton W. D. 1964a The genetical evolution of social behaviour I. J. Theor. Biol. 7: 1-16

Hamilton W. D. 1964b The genetical evolution of social behaviour II. J. Theor. Biol. 7: 17-52

Hamilton W. D. 1972 Altruism and related phenomena, mainly in social insects. Annu. Rev. Ecol. Syst. 3: 193-232

Harris H. 1966 Enzyme polymorphisms in man. Proc. R. Soc. London B164: 298-310

Hubby J. L. and Lewóntin R. C. 1966 A molecular approach to the study of genic heterozygosity in natural populations. I. The number of alleles at different loci in Drosophila pseudoobscura. Genetics 54: $577-94$

Ito Y. 1989 The evolutionary biology of sterile soldier in Aphids. Tree 4: 69-73

Jarvis J. U. M. 1981 Eusociality in a mammal: Cooperative breeding in naked mole-rat colonies. Science 212: $571-573$

Joshi N. V. and Gadagkàr R. 1985 Evolution of sex ratios in social Hymenoptera: Kin selection, local mate competition, polyandry and kin recognition. J. Genet. 64: 41-58

Kukuk P. F. 1989 Evolutionary genetics of a primitively eusocial halictine bee, Dialictus zephyrus. In The genetics of social evolution (eds) M. D. Breed and R. E. Page Jr (Boulder, Colorado: Westview Press) pp. 183-202

Lester L. J. and Selander R. K. 1981 Genetic relatedness and the social organization of Polistes colonies. Am. Nat. 117: 147-166

Lewontin R. C. and Hubby J. L. 1966 A molecular approach to the study of genic heterozygosity in natural populations. II. Amount of variation and degree of heterozygosity in natural populations of Drosophila pseudoobscura. Genetics 54: 595-609

Lin N. and Michener C. D. 1972 Evolution of sociality in insects. Q. Rev. Biol. 47: 131-159

Macnair M. R. 1978 An ESS for the sex ratio in animals, with particular reference to the social Hymenoptera. J. Theor. Biol. 70: 449-459

Metcalf R. A. and Whitt G. S. 1977a Intra-nest relatedness in the social wasp Polistes metricus: A genetic analysis. Behav. Ecol. Sociobiol. 2: 339-351

Metcalf R. A. and Whitt G. S. 1977b Relative inclusive fitness in the social wasp Polistes metricus. Behav. Ecol. Sociobiol. 2: 353-360

Moritz R. F. A. 1986 Two parthenogenetical strategies of laying workers in populations of the honeybee, Apis mellifera (Hymenoptera: Apidae). Entomol. Gener. 11: 159-164

Moritz R. F. A. 1989 Colony level and within colony level selection in honeybees. Behav. Ecol. Sociobiol. 25: $437-444$

Muralidharan K., Shaila M. S. and Gadagkar R. 1986 Evidence for multiple mating in the primitively eusocial wasp Ropalidia marginata (Lep.) (Hymenoptera: Vespidae). J. Genet. 65: 153-158

Nonacs P. 1986 Ant reproductive strategies and sex allocation theory. Q. Rev. Biol. 61: 1-21

Oldroyd B. P. and Rinderer T. E. 1990 Nepotism in honey bees. Nature (London) 346: 707--708

Oster G., Eshel I. and Cohen D. 1977 Worker-queen conflict and the evolution of social insects. Theor. Popul. Biol. 12: 49-85.

Page R. E. Jr 1986 Sperm utilization in social insects. Annu. Rev. Entomol. 31: 297-320

Page R. E. Jr, Breed M. D. and Getz W. M. 1990 Nepotism in honey bees. Nature (London) 346: 707

Page R. E. and Metcalf R. A. 1982 Multiple mating, sperm utilization and social evolution. Am. Nat. 119: 263-281

Page R. E. Jr, and Robinson G. E. 1990 Nepotism in honey bees. Nature (London) 346: 708

Page R. E. Jr, Robinson G. E. and Fondrk M. K. 1989 Genetic specialists, kin recognition and nepotism in honey-bee colonies. Nature (London) 338: 576-579

Pamilo P. 1981 Genetic organization of Formica sanguinea populations. Behav. Ecol. Sociobiol. 9: 45-50

Pamilo P. 1982 Genetic population structure in polygynous formica ants. Heredity 48: 95-106

Pamilo P. 1984 Genotypic correlation and regression in social groups: Multiple alleles, multiple loci and. subdivided populations. Genetics 107: 307-320

Pamilo P. 1987 Sex ratios and the evolution of eusociality in the Hymenoptera. J. Genet. 66: 111-122

Pamilo P. 1989 Estimating relatedness in social groups. Tree 4: 353-355

Pamilo P. and Crozier R. H. 1982 Measuring genetic relatedness in natural populations: Methodology. Theor. Popul. Biol. 21: 171-193 
Pamilo P. and Rosengren R. 1984 Evolution of nesting strategies of ants: genetic evidence from different population types of Formica ants. Biol. J. Linn. Soc. 21: 331-348

Pamilo P. and Varvio-Aho S. 1979 Genetic structure of nests in the ant Formica sanguinea. Behav. Ecol. Sociobiol. 6: 91-98

Pearson B. 1983 Intra-colonial relatedness amongst workers in a population of nests of polygynous ant, Myrmica rubra Latreille. Behav. Ecol. Sociobiol. 12: 1-4

Queller D. C. and Goodnight K. F. 1989 Estimating relatedness using genetic markers. Evolution 43: 258-275

Queller D. C. and Strassmann J. E. 1989 Measuring inclusive fitness in social wasps. In The Genetics of social evolution (eds) M. D. Breed and R. E. Page Jr (Boulder, Colorado: Westview Press) pp. 103-122

Queller D. C., Strassmann J. E. and Hughes C. R. 1988 Genetic relatedness in colonies of tropical wasps with multiple queens. Science 242: 1155-1157

Ratnieks F. L. W. 1988 Reproductive harmony via mutual policing by workers in eusocial hymenoptera. Am. Nat. 132: 217-236

Ratnieks F. L. W. and Visscher P. K. 1989 Worker policing in the honeybee. Nature (London) 342: 796797

Ross K. G. 1986 Kin selection and the problem of sperm utilization in social insects. Nature (London) 323: $798-800$

Ross K. G. and Fletcher D. J. C. 1985 Comparative study of genetic and social structure in two forms of the fire ant Solenopsis invicta (Hymenoptera: Formicidae). Behav. Ecol. Sociobiol. 17: 349-356

Ross K. G. and Matthews R. W. 1989a New evidence for eusociality in the sphecid wasp Microstigmus comes. Anim. Behav. 38: 613-619

Ross K. G. and Matthews R. W. 1989b Population genetic structure and social evolution in the sphecid wasp Microstigmus comes. Am. Nat. 134: 574-598

Ross K. G., Vargo E. L. and Fletcher D. J. C. 1988 Colony genetic structure and queen mating frequency in fire ants of the subgenus Solenopsis (Hymenoptera: Formicidae). Biol. J. Linn. Soc. 34: 105-117

Schwarz M. P. 1987 Intra-colony relatedness and sociality in the allodapine bee Exoneura bicolor. Behav. Ecol. Sociobiol. 21: 387-392

Seger J. 1983 Partial bivoltinism may cause alternating sex-ratio biases that favour eusociality. Nature (London) 301: 59-62

Shermann P. W., Jarvis J. U. M. and Alexander R. D. 1991 The biology of naked mole rat (Princeton, New Jersey: Princeton University Press)

Starr C. K. 1984 Sperm competition, kinship and sociality in the Aculeate Hymenoptera. In Sperm competition and the evolution of animal mating systems (ed.) R. L. Smith (New York: Academic Press) pp. $427-464$

Strassmann J. E., Hughes C. R., Queller D. C., Turillazzi S., Cervo R., Davis S. K. and Goodnight K. F. 1989 'Genetic relatedness in primitively eusocial wasps. Nature (London) 342: 268-270

Stubblefield J. W. and Charnov E. L. 1986 Some conceptual issues in the origin of eusociality. Heredity 57: $181-187$

Trivers R. L. and Hare H. 1976 Haplodiploidy and the evolution of the social insects. Science 191: 249263

Uyenoyama M. K.-and Bengtsson B. O. 1981 Towards a genetic theory for the evolution of sex ratio. II. Haplodiploid and diploid models with sibling and parental control of the brood sex ratio and brood size. Theor. Popul. Biol. 20: 57-79

Venkataraman A. B., Swarnalatha V. B., Nair P. and Gadagkar R. 1988 The mechanism of nestmate discrimination in the tropical social wasp Ropalidia marginata and its implications for the evolution of sociality. Behav. Ecol. Sociobiol. 23: 271-279

Visscher P. K. 1989 A quantitative study of worker reproduction in honey bee colonies. Behav. Ecol. Sociobiol. 25: 247-254

Ward P. S. 1983 Genetic relatedness and colony organization in a species complex of Ponerine ants. Behav. Ecol. Sociobiol. 12: 285--299

Ward P. S. and Taylor R. W. 1981 Allozyme variation, colony structure and genetic relatedness in primitive ant Nothomyrmecia macrops Clark (Hymenoptera: Formicidae). J. Aust. Entomol, Soc. 20: $177-183$

West-Eberhard M. J. 1975 The evolution of social behaviour by kin selection. Q. Rev. Biol. 50: 1-33

West-Eberhard M. J. 1978 Polygyny and the evolution of social behavior in social wasps. J. Kans. Entomol. Soc. 51: 832-856

Wilson E. O. 1971 The insect societies (Cambridge, Mass: Harvard University Press) 